\title{
Optical aspects and energy performance of switchable ethylene-tetrafluoroethylene (ETFE) foil cushions
}

\author{
Jan-Frederik Flor*, Dingming Liu, Yanyi Sun, Paolo Beccarelli, John Chilton and Yupeng Wu* \\ Department of Architecture and Built Environment, Faculty of Engineering, The University of \\ Nottingham, University Park, Nottingham, NG7 2RD, Uk \\ *Corresponding author: Email addresses: jan.flor@nottingham.ac.uk, janflor@gmx.de (J. Flor), \\ Yupeng.Wu@nottingham.ac.uk, Jackwuyp@googlemail.com (Y.Wu)
}

\section{Abstract}

A pneumatic multilayer foil construction with a kinetic shading mechanism has the potential to be an effective response to dynamic climatic factors, such as solar radiation, and therefore moderate the energy consumption of buildings. A parametric study was carried out on a switchable ethylene-tetrafluoroethylene (ETFE) foil cushion with the purpose of investigating the optical performance of an adaptive building envelope and its impact on building energy performance regarding heating, cooling and lighting. Ray-tracing techniques were used to investigate the effects of surface curvature, frit layout and frit properties, on the optical performance of the cushion in open and closed mode. A range of incidence angles for solar radiation were simulated. The results of the simulation showed an angle dependent optical behaviour for both modes. The influence of the dynamic shading mechanism on building energy performance was further evaluated by integrating the optical data obtained for the ETFE foil cushions in a comprehensive energy simulation of a generic atrium building using EnergyPlus. Results suggested that switchable ETFE foil cushions have a higher potential to reduce cooling and heating loads in different climatic regions, compared to conventional glazing solutions (i.e. uncoated double-glazing and reflective double-glazing), while providing good conditions of natural daylighting. Annual energy savings of up to $44.9 \%$ were predicted for the switchable ETFE foil cushion in comparison to reflective double glazing. As such, this study provides additional insight into the optical behaviour of multilayer foil constructions and the factors of design and environment that potentially have a major impact on buildings energy performance.

\section{Key words}

ethylene-tetrafluoroethylene (ETFE) foil ; ray-tracing; transmittance; reflectance; building simulation.

\section{Introduction}

The building sector currently consumes one third of the global final energy [1-4]. Increasing energy demands for commercial and residential building with an expected growth of up to 1.9\%/year [5], raises the necessity for further improvement of the energy performance of buildings. Most of the energy consumed in buildings 
during their operation and maintenance is for space conditioning (approx. 50\%) and lighting (approx. 25\%) [6]. The building envelope, which is the interface between the external and internal environment, is, therefore, a crucial element of the building unit [7-9]. It has huge potential to impact the indoor comfort conditions and to improve the overall energy performance of the building by up to $40 \%$, considering only savings in heating and cooling [10-13]. Much attention has been paid, over recent decades, to passive strategies, which aim to maximize the thermal damping effects of the building mass, while increasing insulation of walls and windows, and reducing thermal bridging of building elements [14-16]. However, the general tendency in architectural design moves towards light and transparent structures, such as membrane and foil structures, which offer high flexibility in form and function [17]. Although challenging in terms of energy efficient design, this solution is often adopted for widespan canopies because of its reduced weight and resulting cost effectiveness [18]. Recent technological advances in control systems, and miniaturization of sensors and actuators, have made the development of actively adaptable building envelopes possible [19]. Moveable parts and transforming elements are fully integrated into the building system and are able to react instantly to changes of the environment or the user demands [20]. These technologies create great opportunities for the optimization of the thermal and optical performance of the building envelope, and improve the energy efficiency of membrane structures [21]. A case study on the "Gardens by the Bay" project in Singapore evaluated the influence of the dynamic operation of shading screens on the hygro-thermal performance of a dome structure covering a botanical garden. It was found that the retractable textile membranes are able to control the incident solar irradiation on the glass envelope, lower the risks of overheating and reduce cooling loads, while maintaining stable natural lighting conditions for the plants throughout the year [22]. Chiu and Lin [23] evaluated the performance of adaptable pre-tensioned textile membrane structures in façades for multi-storey buildings and found that energy savings of up to $13 \%$ were achievable for heating and cooling loads, when compared to conventional static tensioned membranes. Although these results are promising for the development of more energy efficient building envelopes with woven textile membrane materials, few studies have evaluated the potential of adaptable multilayer ethylene tetrafluoroethylene (ETFE) foil constructions. In the past, research has mainly focussed on the structural aspects of ETFE foil constructions, being the most common type a pneumatic structure in the shape of a cushion, which consists of at least two foil layers and is pressurized with air for structural stability. Only recently has the optical and thermal performance of ETFE foil envelopes been addressed in depth in the literature [24-27]. This development, along with the increasing number of built ETFE foil structures, has opened questions about the need for climate adaptive foil systems [28-35]. Due to their light weight (density $=1.75 \mathrm{~g} / \mathrm{cm}^{3}$ ), material thinness $(\mathrm{t}=12-300 \mu \mathrm{m})$ and high transmittance (typically, solar $=93 \%$, visible $=90-$ $97 \%$ for clear foil), [27, 36], ETFE foils present both risks and opportunities for their use in building envelopes. ETFE allows one to build lighter while offering better light transmittance than glass, but uncomfortable conditions such as glare and overheating during the summer season have been reported as potential problems in spaces enclosed by ETFE foil constructions [29, 37]. Added functionalities, achieved using novel printing techniques, and inks and material additives with high reflection, absorption and low emittance properties, are some of the developments of recent years that can be used to improve the thermal and optical performance of ETFE foils and mitigate overheating and glare. Energy savings for cooling demands using a novel ETFE foil with infra-red absorbing coatings were calculated to range between $5 \%$ and $8 \%$ for double and triple layer cushions [38]. Innovative 3D printing techniques applied to the middle layer of triplelayer ETFE foil construction were predicted to achieve even higher energy savings for cooling load of $69 \%$ to 87\%, compared to conventional ETFE foil cushions [39]. While these techniques are mainly passive, the technological trend in the development of building envelopes is moving towards adaptive solutions which respond dynamically to the changing weather conditions, effectively control daylighting and reduce energy demands for cooling [40-47]. The most widely reported strategy for the active control of ETFE foil constructions is the switchable multilayer shading mechanism [27, 48-51]. A model of a switchable triple- 
layer ETFE foil cushion with reflective frit print has been constructed at the laboratory of University of Nottingham, UK (Figure 1).
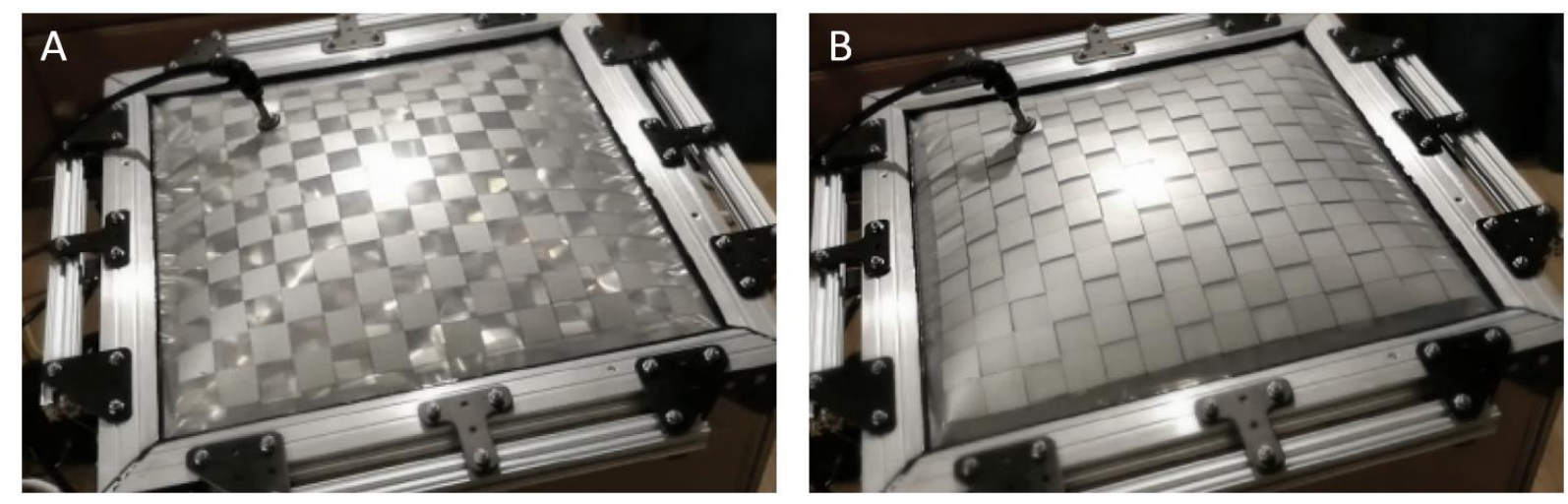

Figure 1: SWITCHABLE ETFE FOIL CUSHION IN OPEN (A) AND CLOSED MODE (B)

ETFE foil cushions function as pneumatic systems that are structurally stabilized by air pressure, which is provided by an air blower unit. The air pressure (in the range 300-600 Pa) keeps the foil tensioned and enables it to withstand external forces, such as wind and snow loads. The ETFE cushions are connected through a pipe network to an air blower, which provides the constant low pressure air flow. The principle of this shading mechanism is based on changing the overall solar transmittance of the cushion unit by controlling the air pressure in the two cavities between the three ETFE foil layers to adjust the position of the moveable middle layer, thus switching between open and closed mode (Fig.2). While adaptable shading mechanisms for textile membranes rely mainly on mechanically retractable systems, which have been applied in many stadia and amphitheatres, the pneumatically controlled mechanisms for inflated foil construction is relatively new. The concept was first introduced by Robbin in 1996 [52], based on a design study by David Geiger from 1977, and more recently, literature has emerged that offers specific project applications incorporating switchable ETFE cushions [27, 53-57].
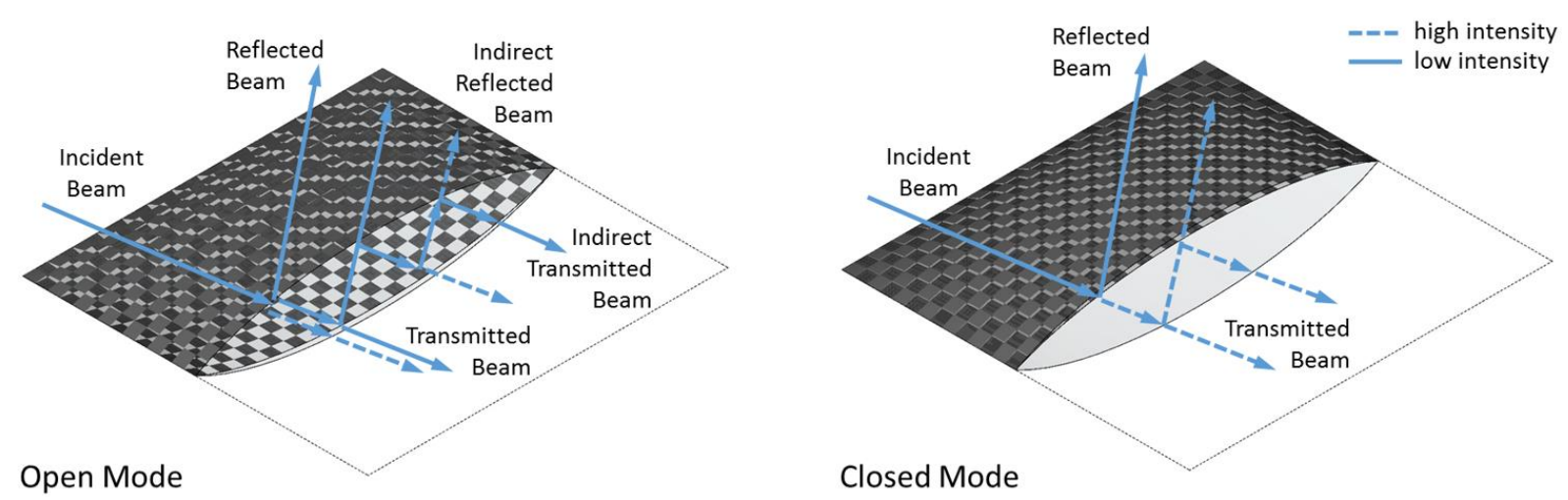

FIGURE 2: TRANSMITTED AND REFLECTED LIGHT BEAMS ON A SWITCHABLE FOIL CUSHION IN OPEN AND CLOSED MODE

Despite having been applied and tested in several buildings ("Duales System World Exposition Pavilion" 2000 [58], “Festo Technology Center" 2000 [49], "Kingsdale School” 2004 [48], "Media-TIC Building" 2010 [59]), very little information has been disclosed on the building physics of this adaptable mechanism, and it is still unclear to what degree the dynamic performance of the foil cushion is contributing to the overall energy performance. This deficiency is related to the fact that the relevant material properties data are not widely available in the public domain, resulting in limited implementation in energy performance simulations. The same applies to data collection of long-term performance and post occupancy studies, which have been carried out only to a limited extent, as in the case of the "Media-Tic Building" where user acceptance and comfort was evaluated [59] but a clear link to the envelope performance could not be established. Although 
extensive research has been carried out, validation of predictive analysis results with specialist software packages and monitoring data remains a challenge for designers and researchers.

The main purpose of this study is to expand the understanding of the environmental behaviour of foil constructions, aiming specifically to investigate the optical performance and the impact on the energy performance of buildings incorporating triple-layer ETFE foil cushions incorporating a dynamic shading mechanism. As part of this comprehensive study a novel method is proposed for the analysis of the switchable ETFE cushions, combining for the first time ray-tracing results with energy simulations. A series of design parameters for ETFE foil cushions, including geometry, curvature and frit prints, were simulated under different solar incidence angles using ray-tracing methods. Ray-tracing has been used previously to examine the optical performance of CFS (Complex Fenestration Systems) [60-62] and offers a practical method to virtually trace solar beams through geometrically complex components such as pneumatic foil constructions. The results of the optical simulations showed a distinctive optical profile for the switching modes of the cushion and provided insights into the angle dependent behaviour of the different designs. This allowed the optical data to be integrated into a building energy model for a realistic atrium building in order to compare frit print design variations of the switchable ETFE foil cushion with common glazing systems. The building simulation software, EnergyPlus [63], was used to predict the energy and lighting performance of the building and moreover explore the performance of the switchable ETFE cushion under different climate conditions. Outcomes of this study deliver advice on the design parameters of switchable ETFE cushions and aim to support decision making of architects and engineers for the system integration in future buildings.

\section{ETFE cushion: geometry and frit pattern design}

As a first step in this study of optical ray-tracing analysis, the cushion geometry of an inflated triple-layer cushion was generated. This was carried out using a combination of 3D modelling software, a series of plugins and in-house developed software components. The form-finding procedure is based on the Updated Reference Strategy (URS). This method generates the equilibrium shape and main stresses for tensioned membrane structures [64]. The specific method of modelling pneumatic multilayer cushions has been described extensively [65]. The synclastic form of all three layers of the cushion is identical and mirrored to form a symmetric geometry where the middle layer offsets the inner or outer layer. The typical generated three-dimensional cushion geometry is illustrated in Figure 3 (left).
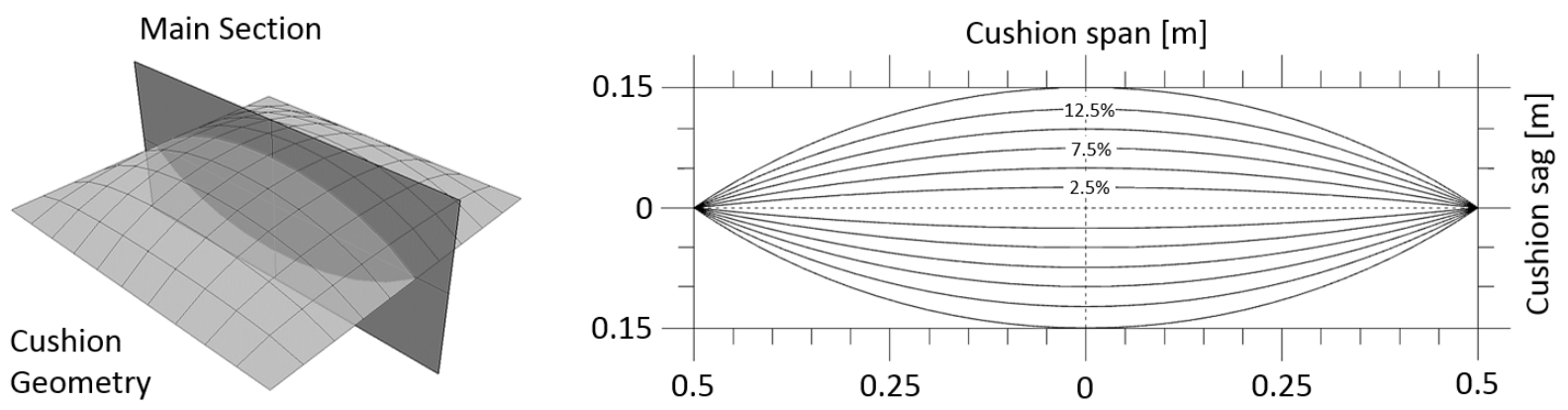

Figure 3: Cushion Geometry (Left) AND VARIABLE SAg to SPAN RATIO (2.5\% to 15\%) OF MAIN SECTION (RIGHT)

For this study, the cushion geometry is limited to a 1 metre by 1 metre planar boundary frame. While these dimensions are relatively small, compared to typical ETFE foil cushions [27], they provide ease for the control and analysis of the ray-tracing simulation. The shape of the cushion geometry was controlled within a range of boundary conditions, where the main parameters are the span, which is the width of the main section, and the sag, which is the maximum displacement of the layer curvature at the centre of the main section 
relative to the span width, given commonly as a percentage. The cushion sag for the centre section was selected based on evidence from the literature $[18,48,49,66]$, ranging in 6 steps from a minimum of $2.5 \%$ to a maximum of $15 \% \mathrm{sag}$, symmetrically on both sides of the horizontal boundary frame. The geometry of the cushion was controlled during the form-finding process by the parameters of surface pre-stress and the inner pressure. The main section geometry of each of the cushion samples is shown in Figure 3, (right).

Printed frit patterns on the clear ETFE foil are an essential design aspect for controlling the optical performance of multilayer foil constructions. The silver ink, which is used normally for the frit, is highly reflective and printed onto the foil surface in patterns which are designed to cover a specific area ratio in order to reflect a defined percentage of incident light and energy. A variety of transmittance gradients can be achieved when the frit ink is printed in different densities on the ETFE foil. The total transmittance of the foil and cushion is also dependent on the frit print coverage per area [29]. Normally, common dot or hexagon frit patterns cover $20 \%$ to $75 \%$ of the foil surface area and thus result in an overall transmittance ranging between $39 \%$ and $74 \%$. But, in this study, a pattern is required for the kinetic system that covers nearly $100 \%$ of the surface area when the positive and negative print, of both the outer and middle layer, are overlapped (Figure 4, left). The inner layer is of clear material without any frit. Design variations of this layout, including different geometries and grades of print densities, are available in the building industry. The currently most commonly used design for this shading system is printed with dense squares of approx. $100 \times 100 \mathrm{~mm}$ alternating with clear squares, approx. $70 \times 70 \mathrm{~mm}$ that have a less densely printed border of $15 \mathrm{~mm}$ all round. Therefore, it covers approx. $50 \%$ with dense frit, $25 \%$ clear and $25 \%$ with less dense frit. However, for this study a simplified layout of a chequerboard pattern covering $50 \%$ of each layer was adopted. This layout was applied onto the generated meshes with three different grid sizes $(100 \mathrm{~mm}, 50 \mathrm{~mm}, 33 \mathrm{~mm})$, which represent a variation of commercial frit designs. The projection of the frit pattern onto the cushion geometry was inspired by the method proposed by Roudsari and Waelkens [67]. It was necessary, though, to modify the method according to the model requirements of the ray tracing simulation. Therefore the geometric deformation of the frit pattern layout caused by the double curved surface, although kept to a minimum, had to be neglected for this study. The full array of design samples for the simulation can be seen in Figure 4 (right).
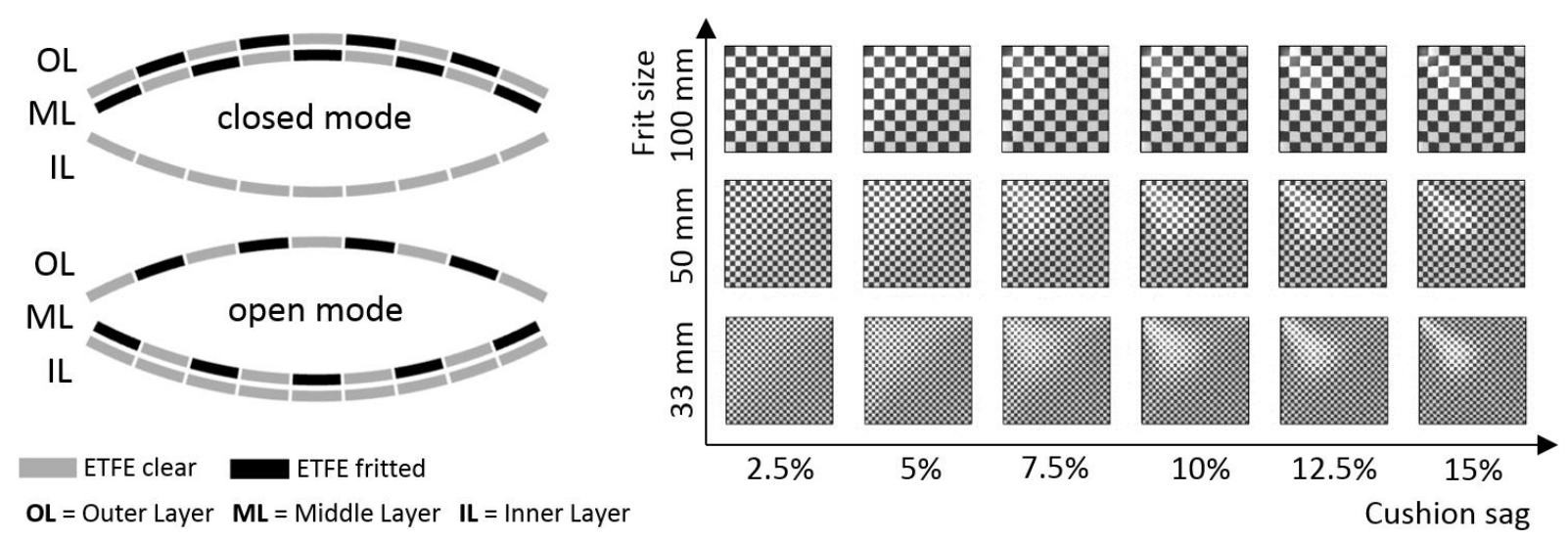

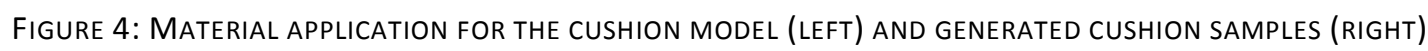

\section{Optical model for ETFE}

Ray tracing is a computational method used to calculate the trajectory of light and the refraction, reflection and scattering effects through optical systems by the representation of beams. The theoretical base for ray- 
tracing was initially developed by Spencer and Murty [68] and is now a widely accepted technique to aid the design of solar energy systems and solar façades [69-72]. The use of ray-tracing for the analysis of the optical behaviour of the multilayer cushion system seemed, therefore, appropriate in this study. The parametric setup of the study was designed to investigate the optical performance of switchable ETFE foil cushions in open and closed mode under different solar incidence angles and to carry out a $360^{\circ}$ analysis. Design variations of the ETFE foil cushions, like sag and frit pattern, were considered in the study, and the effect of the optical properties of printed frit ink on the optical performance of the cushion was investigated in depth. Based on an intensive review, the absorptance and reflectance for ETFE and frit print was assigned to the cushion geometries [26, 27, 29, 73-75]. While precise optical data for clear ETFE foil is widely available, information on the properties of printed ETFE foil is somewhat limited. In order to further deepen the understanding about the impact of frit ink on the overall optical performance of the ETFE foil cushion, theoretical variations of frit transmittance and reflectance were added as a parameter to the study. In addition to the collected data from the literature for printed [21] and clear [22] ETFE foil, the transmittance of a notional frit ink was modified gradually from $5 \%$ to $95 \%$ with interval of $15 \%$, while the reflectance was correspondingly reduced from $95 \%$ to $5 \%$. The selected optical property variations for the clear and printed ETFE foil are shown in Table 1.

TABLE 1: OPTICAL PROPERTIES OF FRIT PRINTS AND MATERIAL FOR RAY-TRACING SIMULATION INPUT (*[26], **[27])

\begin{tabular}{|c|c|c|c|c|}
\hline Data Source & Material Code & Transmittance [\%] & Reflectance [\%] & Absorptance [\%] \\
\hline \hline \multirow{4}{*}{$\begin{array}{c}\text { Theoretical } \\
\text { Variations }\end{array}$} & Frit Print 1 & 5 & 95 & 0 \\
\cline { 2 - 5 } & Frit Print 2 & 20 & 80 & 0 \\
\cline { 2 - 5 } & Frit Print 3 & 35 & 65 & 0 \\
\cline { 2 - 5 } & Frit Print 4 & 50 & 50 & 0 \\
\cline { 2 - 5 } & Frit Print 5 & 65 & 35 & 0 \\
\cline { 2 - 5 } & Frit Print 6 & 80 & 20 & 0 \\
\cline { 2 - 5 } & Frit Print 7 & 95 & 5 & 0 \\
\hline \hline \multirow{4}{*}{ Literature } & Frit Print 8* & 5 & 61 & 34 \\
\cline { 2 - 5 } & ETFE clear** & 93 & 6 & 1 \\
\hline
\end{tabular}

For the ray-tracing simulation, radiation with a known intensity was assumed, incident to the surface of the ETFE system, with each ray carrying the same amount of energy. After the initial process of ray independence testing, 1,000,000 rays were applied on the square frame aperture containing the ETFE foil cushion. The beams were emitted from a one metre square grid with one metre distance to the horizontal centre section of the cushion. The dimensions of the radiation source were corrected to adjust for the changing incidence angle, thus projecting beams only onto the surface, while maintaining the same flux ratio. The beams were traced allowing multiple reflections. The energy flux of the transmitted and reflected beams was collected and quantified while the absorbed energy was calculated according to the law of conservation of energy. Figure 5 illustrates the ray-tracing simulation for the proposed ETFE foil cushion at a solar incidence angle of $90^{\circ}$. 

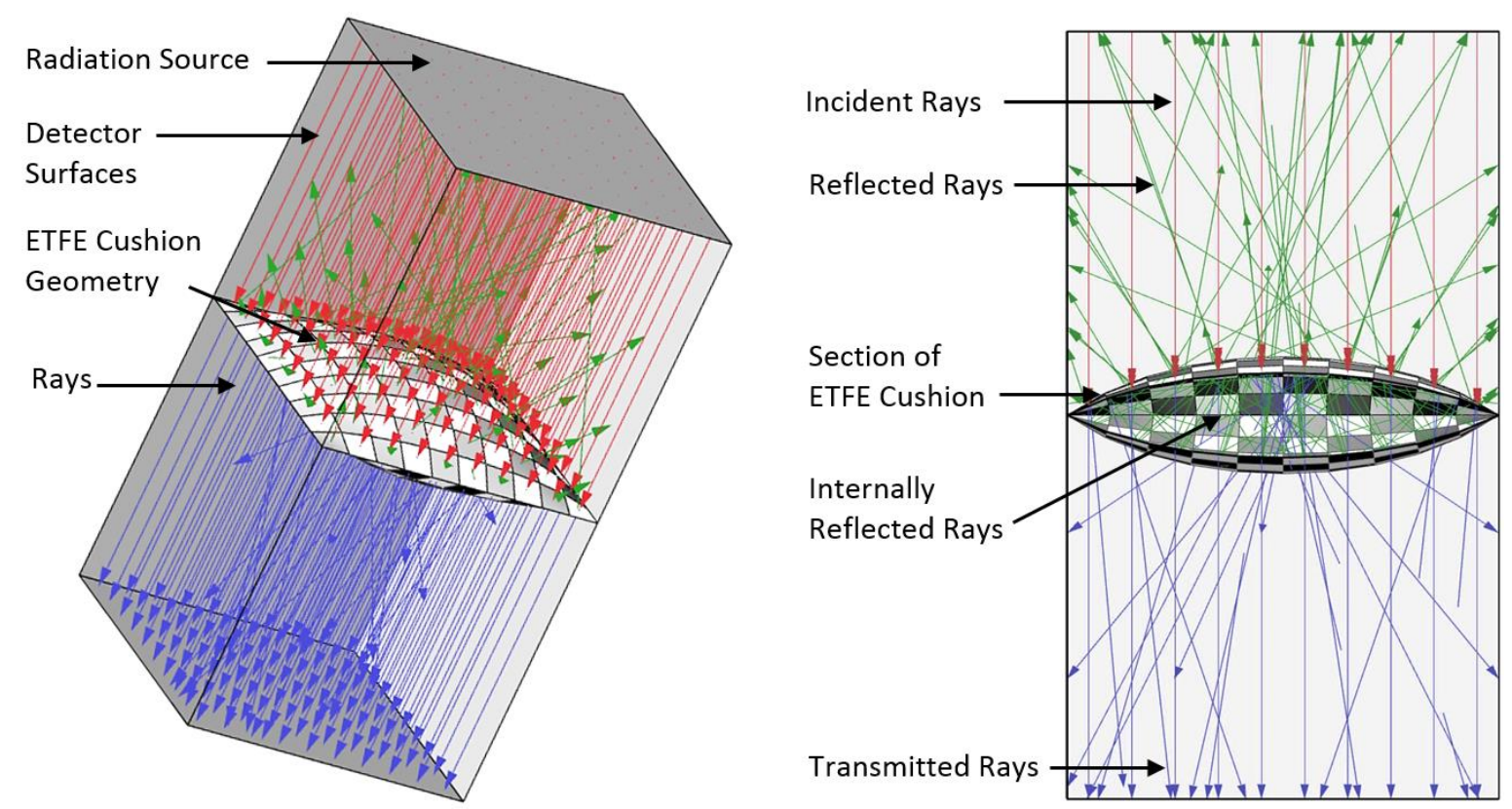

FIGURE 5: RAY-TRACING 3D MODEL (LEFT) AND ETFE CUSHION SECTION WITH TRACED RAYS (RIGHT)

The initial sample group consisted of 36 different cushion models in open and in closed mode, corresponding to the three different frit grid sizes and six sag variations. The performance of all cushion samples was compared for the open and closed position while only three sag ratios $(5 \%, 10 \%, 15 \%)$ were selected for further scenario simulations. During the following simulation round, the optical properties and the grid geometry of the frit print was kept constant, simulating the transmittance of the cushion with solar rays incident from different altitude angles. The rays were traced in steps of $20^{\circ}$ ranging from angles of $10^{\circ}$ to $90^{\circ}$, normal to the rectangular boundary frame of the cushion. In a further step, the effect of the frit print grid size variation, in combination with different sag ratios, was evaluated under a single incidence angle. Grid sizes of $33 \mathrm{~mm}, 50 \mathrm{~mm}$ and $100 \mathrm{~mm}$ were tested on six different cushion geometries with a sag of $2.5 \%, 5.0 \%$, $7.5 \%, 10.0 \%, 12.5 \%$ and $15.0 \%$ under an incidence angle, perpendicular to the horizontal plane of the cushions. For both scenarios only the optical properties gathered from the literature were considered in the simulation. In order to evaluate, as well, the three-dimensional performance, multi-angle scenarios including polar ranges, were set up. For all further simulations within these 3D scenarios, a single model with a sag of $10 \%$ and a frit grid size of $50 \mathrm{~mm}$ was selected. This selection was considered appropriate to limit the influence of other parameters and reduce the sample size i.e. simulation time. The theoretical frit print variations were assigned to the cushion and the optical performance compared with the material data selection from the literature. The scenarios ranged in steps of $15^{\circ}$ from an azimuth angle of $0^{\circ}$ to $45^{\circ}$ and a altitude angle of $15^{\circ}$ to $90^{\circ}$, relative to the horizontal plane of the cushion. The symmetry of the model geometry allowed extrapolation for all other hemispheric incidence angles (Figure 6). 

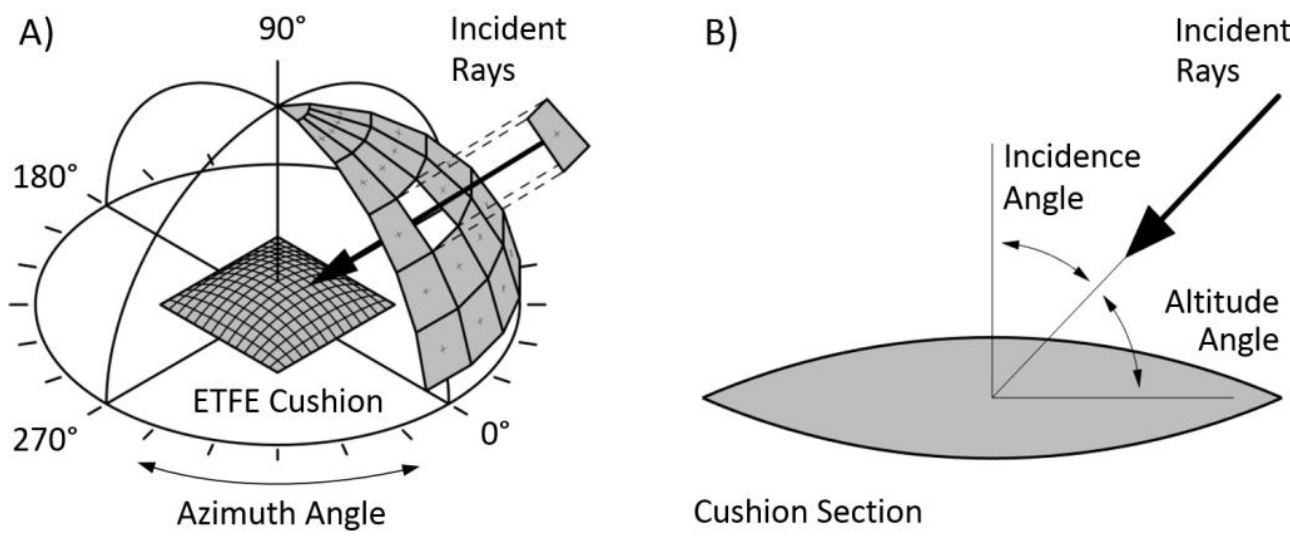

Cushion Section

FIGURE 6: INCIDENCE ANGLES OF RAYS ON CUSHION GEOMETRY, 3D VIEW (A) AND SECTION (B)

The analysis of the optical performance of different cushion designs over a wide range of solar angles provided the basis to conduct a comprehensive energy simulation of a whole building incorporating switchable ETFE foil glazing systems. This predictive performance simulation with selected material scenarios is described in the following section.

\section{Building simulation model}

In this study, EnergyPlus [63] was used to explore the daylight and energy performance of an atrium building with applied switchable ETFE foil cushions. The model for the energy simulation is based on a real building on Jubilee Campus at the University of Nottingham, UK. This multi-use atrium building comprises three zones. Zone 1 , the atrium, is the target zone, which is used as a student dining hall. It is sandwiched between two other zones (i.e. Zone 2 and Zone 3), which are three-storey lecture buildings. Other than the floor, all the surfaces in Zone 1 that interact with the external environment are constructed with glazing. In a series of simulation scenarios, the glazing façade of the atrium was replaced by switchable ETFE foil cushions with different frit print types (scenario names: cushion with frit print " $n$ "). The thermal, daylight and energy performance of the target zone was compared with conventional clear double-glazing (scenario named: clear DG). In order to provide well-rounded comparison, one more scenario was used as reference, where all the clear double-glazing in the target zone was replaced by reflective glazing (scenario named: reflective DG). The energy simulation model of the building is shown in Fig. 7 A) and B).

A)

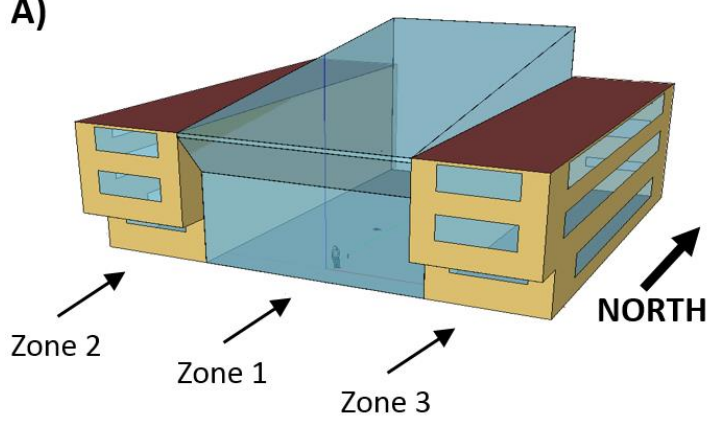

B)

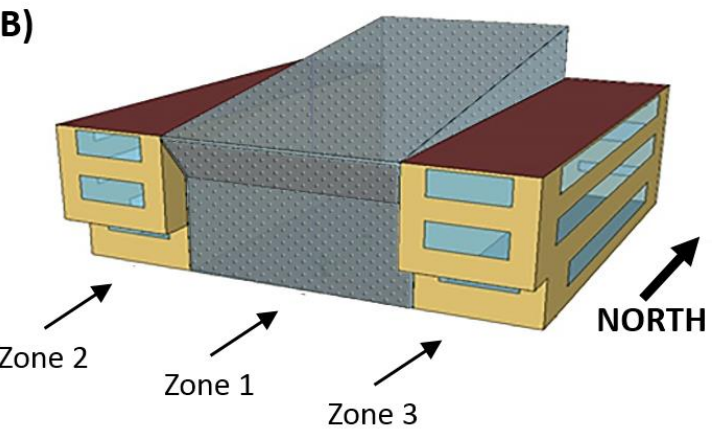

FIGURE 7: BUILDING MODEL FOR ENERGY SIMULATION WITH GLAZING SYSTEMS IN ZONE 1 (A); ZONE 1 GLAZING IS REPLACED WITH SWITCHABLE ETFE CUSHION (B)

The atrium building is constructed with high performance materials and the U-value of the wall and roof building components comply with the standards of common building regulations [76]. Optical and thermal material properties of the ETFE foil cushions with frit print 8 are based on findings from the literature [26, 
27], while cushions with frit print 1, 3 and 5 represent theoretical modifications of the selected frit print with low, medium and high frit transmittance, respectively. A summary of the optical and U-value data for the building components used for the simulation is shown in Table 2.

TABLE 2: OPTICAL AND THERMAL PROPERTIES OF BUILDING COMPONENTS AND MATERIALS FOR ENERGY SIMULATION INPUT

\begin{tabular}{|c|c|c|c|c|c|c|c|c|}
\hline Component - Type & Mode & $\begin{array}{c}T_{v i s} \\
{[\%]} \\
\end{array}$ & $\begin{array}{c}\boldsymbol{R}_{v i s} \\
{[\%]} \\
\end{array}$ & $\begin{array}{l}T_{\text {sol }} \\
{[\%]} \\
\end{array}$ & $\begin{array}{c}\boldsymbol{R}_{\text {sol }} \\
{[\%]} \\
\end{array}$ & $\begin{array}{c}A_{\text {sol }} \\
{[\%]}\end{array}$ & $\begin{array}{c}\text { SHGC } \\
{[\%]}\end{array}$ & $\begin{array}{l}\text { U-Value } \\
{\left[\mathrm{W} / \mathrm{m}^{2} \mathrm{~K}\right]}\end{array}$ \\
\hline Wall & $\mathrm{N} / \mathrm{A}$ & - & - & - & - & - & - & 0.3 \\
\hline Floor & N/A & - & - & - & - & - & - & 0.2 \\
\hline Roof & N/A & - & - & - & - & - & - & 0.2 \\
\hline Clear DG (clear /clear) & N/A & 81.4 & 15.0 & 70.0 & 12.7 & 17.4 & 76.5 & $2.3-2.4 *$ \\
\hline $\begin{array}{l}\text { Reflective DG (Reflective/ } \\
\text { clear) }\end{array}$ & N/A & 32.5 & 39.2 & 22.5 & 42.5 & 34.9 & 29.2 & $2.3-2.4 *$ \\
\hline \multirow{2}{*}{ Cushion with frit print 1} & open & 31.0 & 67.1 & 31.0 & 67.1 & 2.0 & 31.5 & \multirow{2}{*}{$2.7-2.8^{*}$} \\
\hline & closed & 9.0 & 80.0 & 9.0 & 88.3 & 2.9 & 9.7 & \\
\hline \multirow{2}{*}{ Cushion with frit print 3} & open & 46.0 & 52.5 & 46.0 & 52.4 & 2.0 & 46.2 & \multirow{2}{*}{$2.7-2.8 *$} \\
\hline & closed & 36.0 & 60.6 & 36.0 & 61.7 & 2.5 & 36.4 & \\
\hline \multirow{2}{*}{ Cushion with frit print 5} & open & 65.0 & 33.4 & 65.0 & 33.3 & 2.1 & 65.4 & \multirow{2}{*}{$2.7-2.8 *$} \\
\hline & closed & 62.0 & 36.0 & 62.0 & 36.5 & 1.7 & 62.3 & \\
\hline \multirow{2}{*}{ Cushion with frit print $8 *$} & open & 19.4 & 38.4 & 19.4 & 45.7 & 34.9 & 29.4 & \multirow{2}{*}{$2.7-2.8 *$} \\
\hline & closed & 1.9 & 58.4 & 1.9 & 58.0 & 40.0 & 7.8 & \\
\hline
\end{tabular}

* U-value of glazing have slight variation according to the change of tilt angle within $0^{\circ}$ to $90^{\circ}$.

The simulation was carried out under cool temperate and warm weather conditions, represented by Birmingham (UK) and Barcelona (Spain) climate data. The climate of Barcelona is warm, with monthly average ambient temperatures ranging between $8^{\circ} \mathrm{C}$ and $23^{\circ} \mathrm{C}$ throughout the year, and a high monthly average incident solar radiation rate, with an annual variation between 93 and $284 \mathrm{~W} / \mathrm{m}^{2}$. Birmingham, representing cold climate in this study, has a mean outside temperature in the range of $3^{\circ} \mathrm{C}$ to $17^{\circ} \mathrm{C}$ and solar radiation rate from 27 to $225 \mathrm{~W} / \mathrm{m}^{2}$. The annual monthly average data for temperature and incident solar radiation of the two locations is shown in Figure 8. 

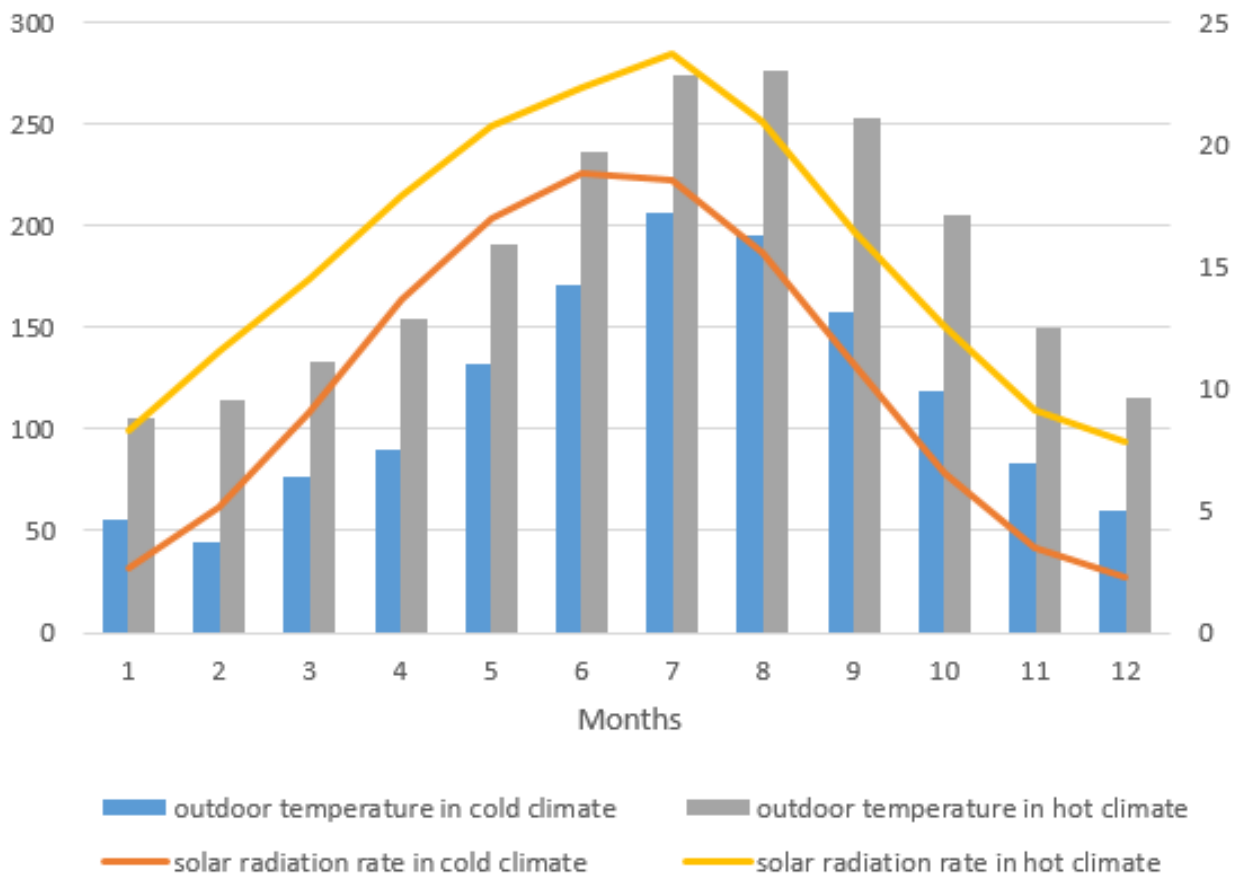

Figure 8: Monthly aVerage Weather datA for Birmingham (COld CLIMATE) AND BARCELONA (hot CLIMATE) EXTRACTED FROM [77]

The parameters in the EnergyPlus simulation were set for Zone 1 according to the standard of CIBSE guide A [78] to meet the requirements for a student dining hall. A summary of the most relevant settings is listed in Table 3.

TABLE 3: BUILDING PARAMETER SETTINGS FOR ENERGY SIMULATION [78]

\begin{tabular}{ll}
\hline Parameter & Value \\
\hline Zone Volume & $3331.75 \mathrm{~m}^{2}$ \\
Occupancy Density & $3.0 \mathrm{~m}^{2}$ per person \\
Equipment Sensible Heat Gain Density & $5.0 \mathrm{~W} / \mathrm{m}^{2}$ \\
Lighting Power Density & $7.0 \mathrm{~W} / \mathrm{m}^{2}$ \\
Standard Maintained Illuminance & $200 \mathrm{lux}$ \\
Infiltration Rate & $0.25 \mathrm{~h}^{-1}$ \\
Cooling Set Point & $24.5^{\circ} \mathrm{C}$ \\
Heating Set Point & $22.0^{\circ} \mathrm{C}$ \\
\hline
\end{tabular}

For the purpose simulating the switchable mechanism of the ETFE foil cushions, a custom-made script that implements an Energy Management System (EMS) was developed within the software interface of EnergyPlus. The script controls the switching mechanism of the ETFE foil cushions with a virtual daylighting illuminance sensor which is located in the centre of the working plane in Zone 1 . The sensor detects daylighting illuminance within the virtual model, records the data every 10 minutes and compares the target value to decide which control command will be executed. The control centre operates with the control function @TrendMax which will send the order "shift to close mode" if the maximum illuminance has passed beyond 2000 lux (above the comfortable illuminance level) during the last hour. If this condition is not fulfilled the order "shift to open mode" will be sent to the ETFE foil cushion instead. Annual simulations were 
conducted under warm and cold temperate weather scenarios. The effect of the different material options on the energy and lighting performance are analysed and discussed in the following sections.

\section{Results and discussion}

The present study was designed to determine the effect of design parameters, like geometry and frit print, on the optical performance of a multilayer ETFE foil cushion with a kinetic shading mechanism. It was further hypothesized that such a switchable glazing system may improve the overall energy performance of buildings and enhance comfortable lighting conditions. In the following sections, the results of the ray-tracing and energy simulations relating to these questions are presented and the performance of the ETFE foil cushion under different environmental scenarios is discussed.

\subsection{The effects of sag and frit pattern on the optical performance of an ETFE foil cushion with switchable mechanism}

The effects of sag and frit pattern on the optical performance of an ETFE foil cushion with switchable mechanism are discussed in the following section. At first, three different cushion geometries with a sag ratio of $5 \%, 10 \%$ and $15 \%$ were simulated in open and closed mode with material and frit print properties collected from the literature [26, 27], (Scenario of Frit Print 8). Solar angles ranging in steps of $20^{\circ}$ from a nearly horizontal angle of $10^{\circ}$ to $90^{\circ}$, perpendicular to the horizontal cushion plane, were simulated using raytracing. Figure 9 (left and right) shows the total transmittance of the ETFE foil cushions in the open and closed mode. As can be seen, the optical performance of the cushion in open and closed mode showed a clearly distinctive behaviour with a characteristic higher transmittance in open mode. In the open mode transmittance values from a minimum of $2.8 \%$ to a maximum of $24.0 \%$ were obtained, while in the closed mode the transmittance ranged between a minimum of $0.1 \%$ to a maximum of $7.0 \%$ (Figure 9). While the sag ratios have only minor effect on the optical performance of the cushion it can be seen from the results that the optical behaviour is strongly dependent on the incidence angle, an observation which had also been noted for single layer structures in previous studies [30, 74, 79]. The results from Figure 9 showed a general trend of decreasing transmittance and increasing reflectance for an ascending altitude angle which might be explained by factors, such as the surface curvature of the cushion, internal reflections and overlaps between the two fritted layers. Higher transmittance values at lower angles might be explained by an increased optical permeability of the cushion, allowing for unobstructed, direct solar ray paths through the reflective frit patterns of the printed layers. 
Open Mode - 50 x 50 mm Frit Layout

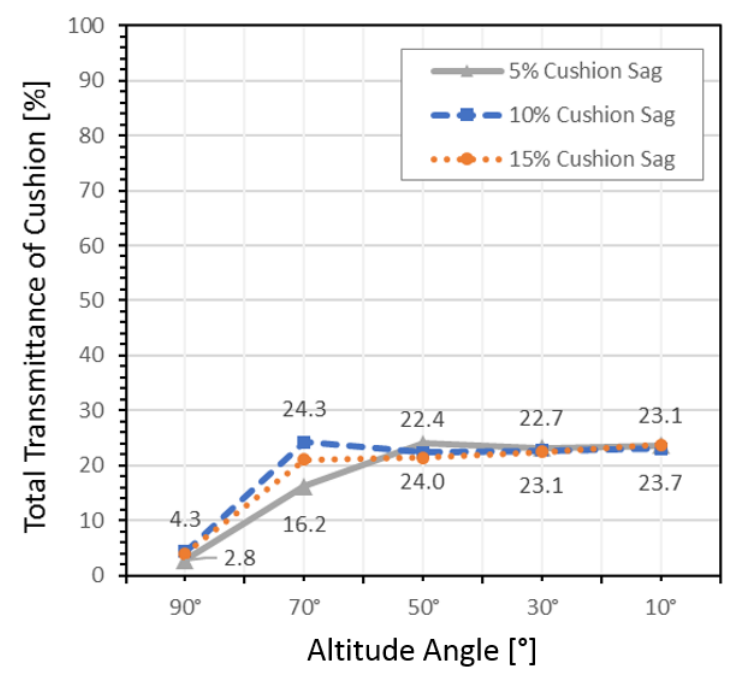

Closed Mode - 50 x 50 mm Frit Layout

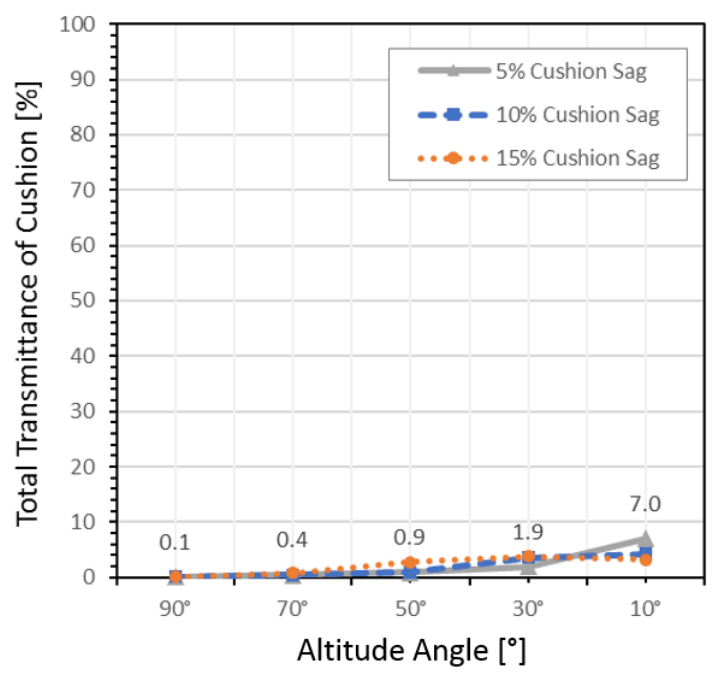

FIGURE 9: OPTICAL PERFORMANCE OF SWITCHABLE TRIPLE-LAYER CUSHION (50 X 50 MM FRIT LAYOUT) WITH VARYING SAG GEOMETRY - ANGLE DEPENDENT TRANSMITTANCE IN OPEN (LEFT) AND CLOSED MODE (RIGHT)

In a next step the combined effect of the frit print grid size with variations of the cushion geometry was evaluated at a perpendicular incidence angle. From Figure 10 it can be seen that the general tendency in open mode is of lower transmittance $(0.6 \%)$ for smaller sag ratios and higher transmittance $(4.3 \%)$ for bigger sag ratios. The effect of the grid size was minimal, showing only a small increase of transmittance $(0.8 \%)$ for bigger frit grid-sizes. For the closed mode under the same incidence angle a constant transmittance close to zero and a reflectance of $60 \%$ was found with little variance for all simulated models (Figure 10).

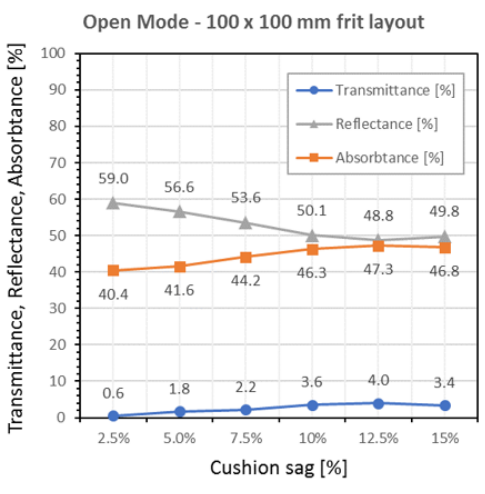

Closed Mode - 100 x $100 \mathrm{~mm}$ frit layout

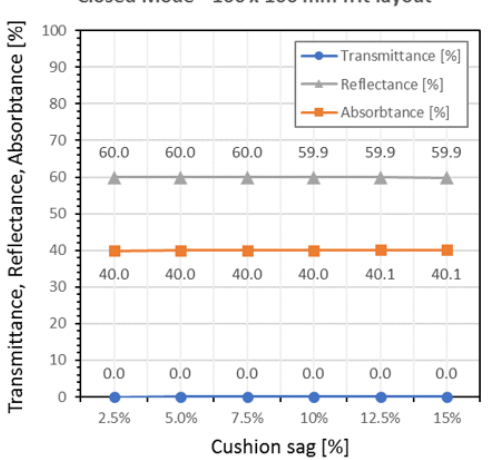

Open Mode - 50 x $50 \mathrm{~mm}$ frit layout

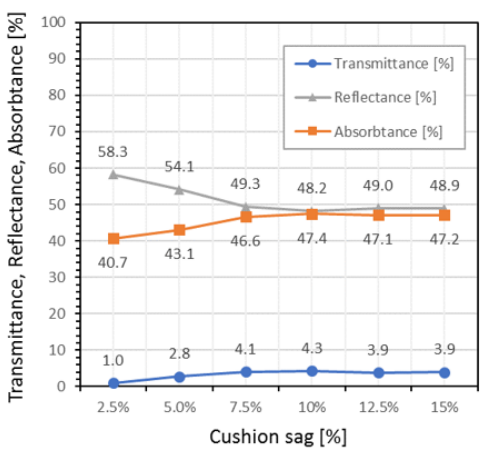

Closed Mode - 50 x $50 \mathrm{~mm}$ frit layout

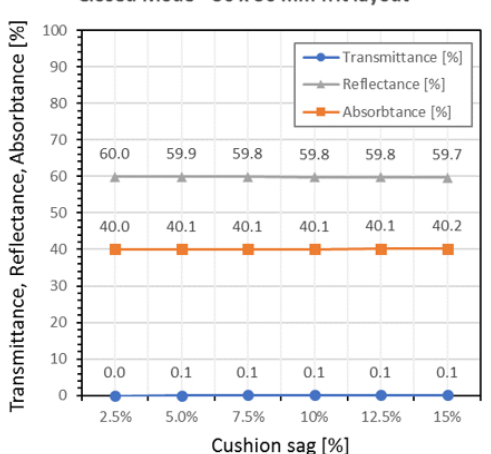

Open Mode $33 \times 33 \mathrm{~mm}$ frit layout

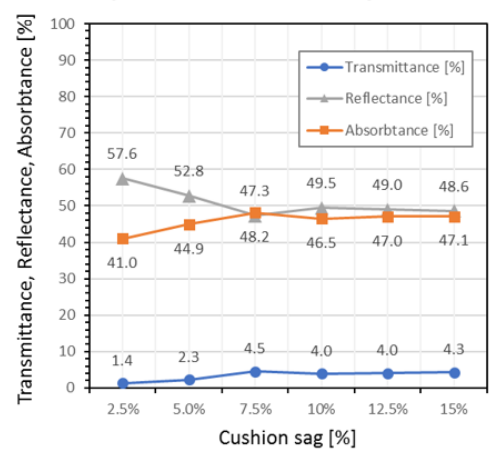

Closed Mode - 33 x $33 \mathrm{~mm}$ frit layout

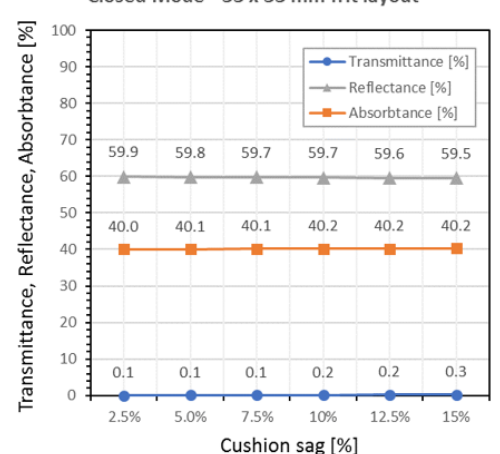

FIGURE 10: OPTICAL PERFORMANCE OF SWITCHABLE TRIPLE-LAYER CUSHION (10\% SAG WITH VARYING FRIT LAYOUT) TRANSMITTANCE AT PERPENDICULAR INCIDENCE ANGLE IN OPEN AND CLOSED MODE

In general, the obtained transmittance values for the perpendicular angle were significantly lower compared to those all other incidence angles. However, these results only represent an extreme case, in real roofs the solar incidence will normally be below the zenith, except for latitudinal regions close to the equator. The 
transmittance of a switchable cushion in open mode ranges typically between $20 \%$ to $25 \%$, as can be seen from Figure 9. The relatively small difference of energy flux, of less than $4 \%$, for all the combinations of cushion geometries and frit pattern (Fig. 10), led to the conclusion that the grid size has only little influence on the performance. Therefore, the grid size parameter was not considered for the further analysis. Nevertheless, from a perspective of lighting comfort it might be beneficial to opt for a smaller grid size as light will be transmitted in a more homogenous distribution.

\subsection{Optical performance of switchable ETFE foil cushion with variations of frit print properties at different incidence angles}

From the previous discussion, it can be seen that design parameters, like sag and frit pattern size, have only a relatively small influence on the optical performance of the ETFE foil cushion, while the incidence angle of solar radiation has a higher impact on the transmittance. In addition to these preliminary results, it is important to ask if other factors like the optical frit print properties can contribute to an improved performance of the switchable cushion. What follows is a description of the results obtained from an amplified study on multiple cushion models with gradually modified optical frit print properties. The simulations were conducted under a range of three-dimensional ray-tracing scenarios that produced hemispherical mean transmittance values for the cushions with different frit print types applied. Seven virtual frit print types were generated, each with a gradually increasing transmittance and simultaneously decreasing reflectance. The absorptance was neglected and kept constant at a value of zero, in order to limit the number of influencing parameters. The optical properties from Liu's [21] and Knipper's [22] work (frit print type 8) were included in the study as a reference for comparison. The testing scenarios comprised a range of angles for incident rays in steps of $15^{\circ}$ from $15^{\circ}$ to $90^{\circ}$ in a vertical plane and from $15^{\circ}$ to $45^{\circ}$ in a horizontal plane. The predicted optical performance of the cushion with $10 \% \mathrm{sag}, 50 \times 50 \mathrm{~mm}$ frit layout with various frit print is illustrated in Figure 11. As expected, the cushions with an assigned frit print with a high transmittance displayed also a high overall transmittance, and the inverse behaviour for high reflective frit prints was the case. It can also be seen from the graphs of Figure 11 that the angle dependent optical behaviour is characteristic in all models. Similar trends to the simulation scenarios from the previous section can be observed. However, a more pronounced decrease of the overall transmittance rate at higher altitude angles $\left(60^{\circ}\right.$ to $\left.90^{\circ}\right)$ is evident in cushions with frit prints with higher reflectance and lower transmittance. A significant increase in overall transmittance was observed at high altitude angles, with almost $10 \%$ at $45^{\circ}$ azimuth angle in the closed mode. The effect seems to increase with a changing azimuth angle, reaching a maximum optical permeability at azimuth angle of $45^{\circ}$, where the direction of incident rays is diagonal, relative to the rectangular frit pattern. 
Open mode - Azimuth Angle $0^{\circ}$

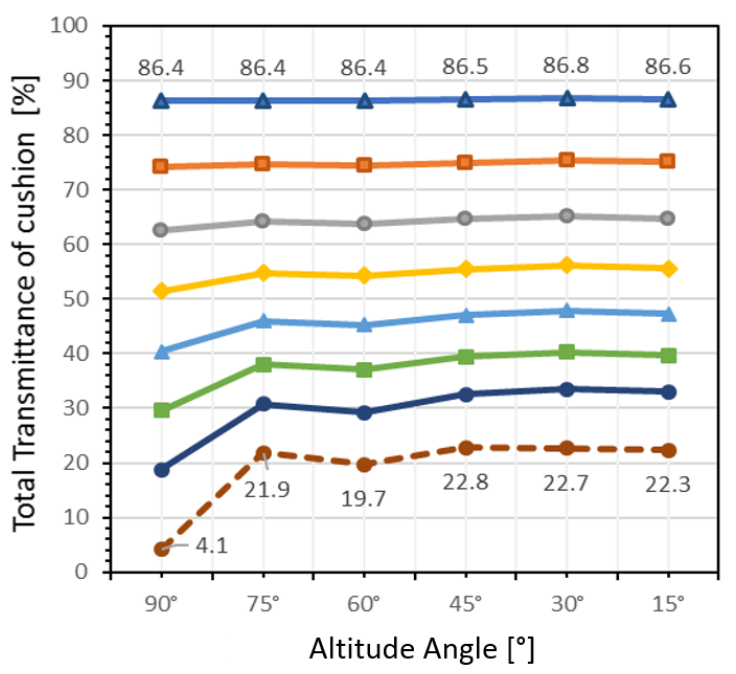

Open Mode - Azimuth Angle $15^{\circ}$

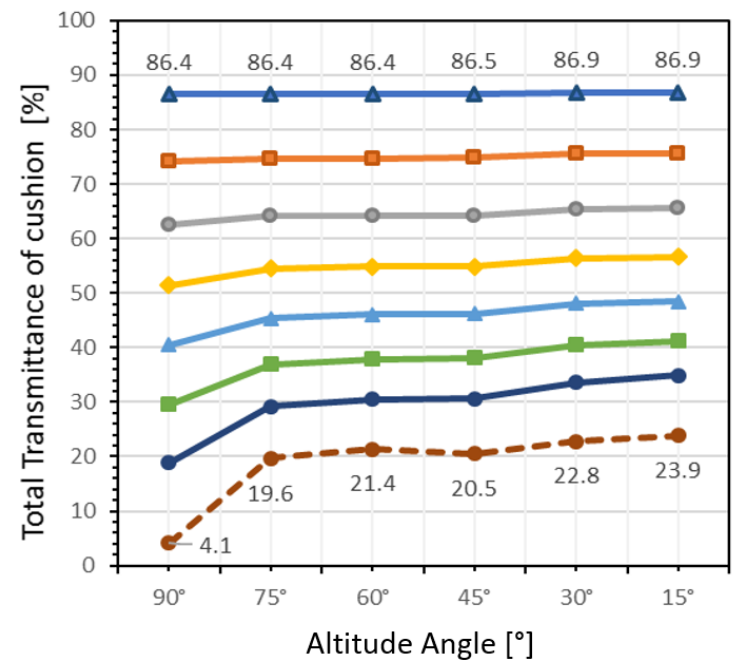

Open Mode - Azimuth Angle $30^{\circ}$

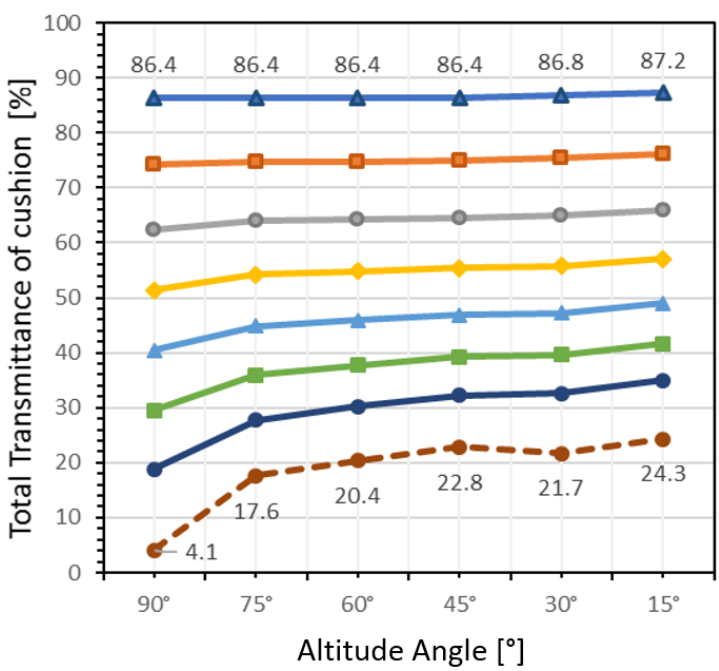

Closed Mode - Azimuth Angle $0^{\circ}$

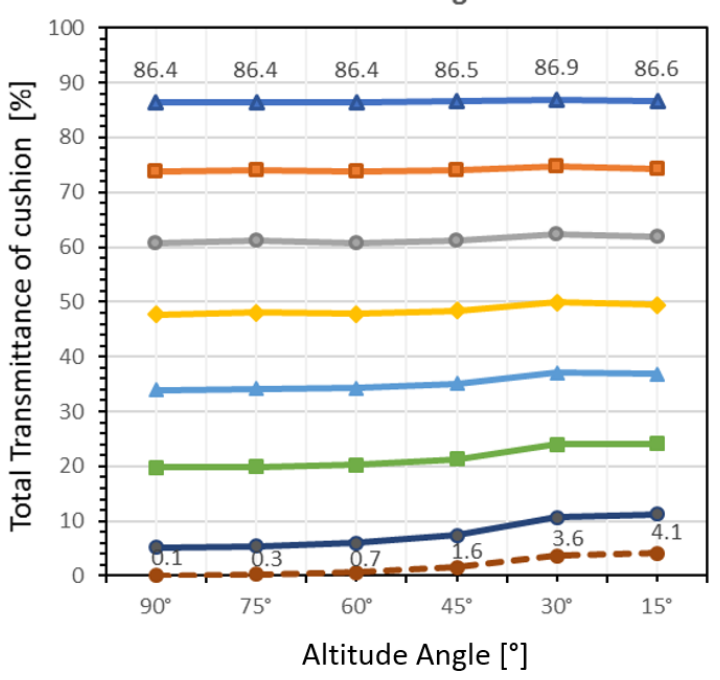

Closed Mode - Azimuth Angle $15^{\circ}$

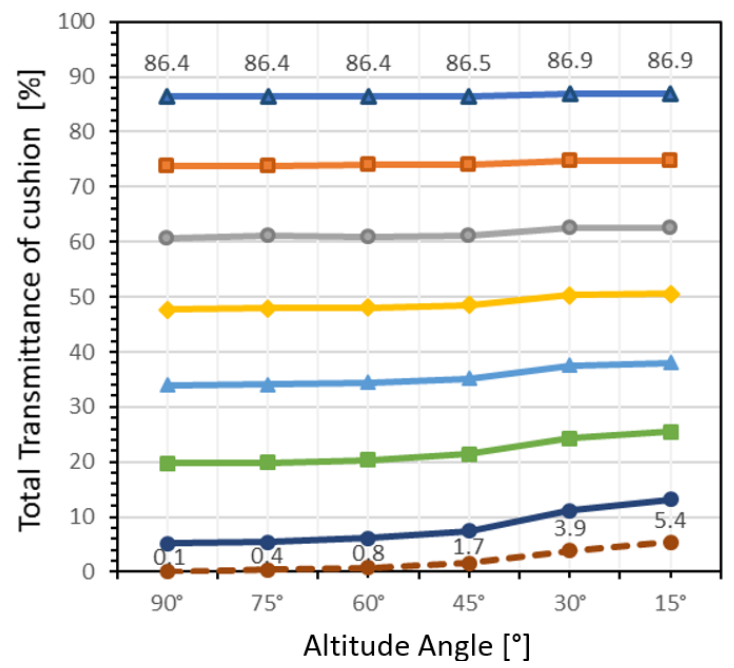

Closed Mode - Azimuth Angle $30^{\circ}$

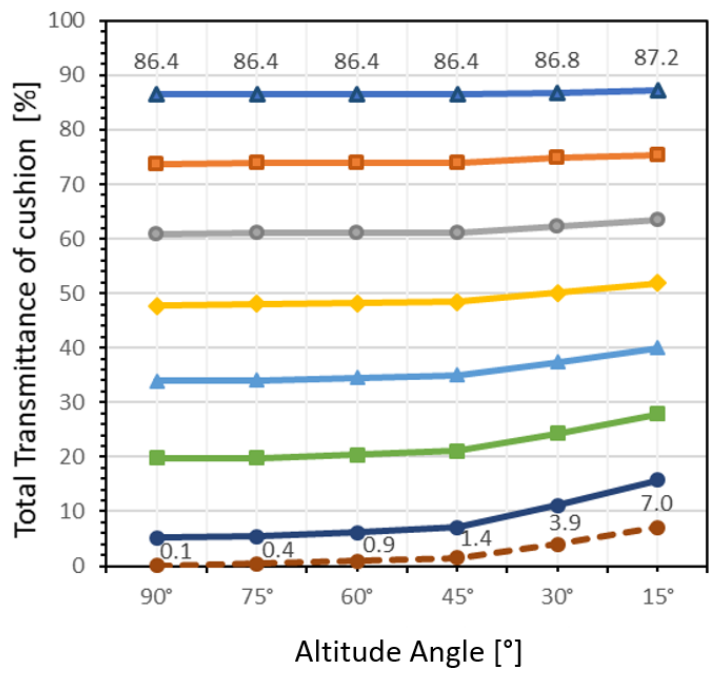


Open Mode - Azimuth Angle 45ำ

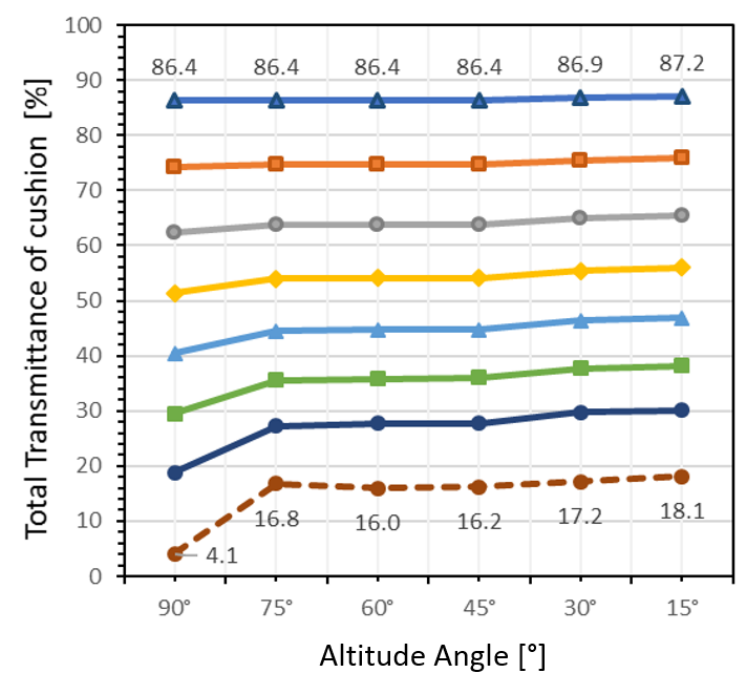

Closed Mode - Azimuth Angle $45^{\circ}$

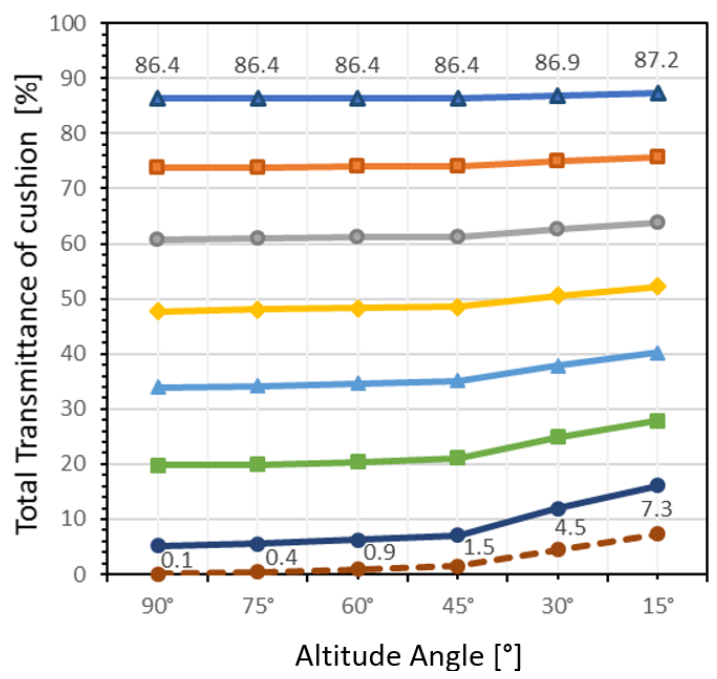

$$
\begin{aligned}
& \text { Legend: } \quad \text { — Frit print type 3: T 35\%, R 65\%, A 0\% } \\
& \text { - Frit print type 1: T 5\%, R 95\%, A 0\% } \\
& \text { - Frit print type 2: T 20\%, R } 80 \%, \text { A } 0 \%
\end{aligned}
$$

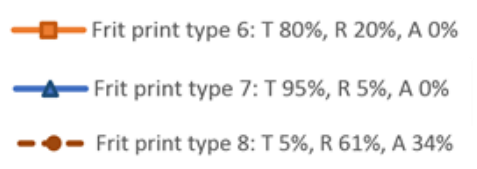

FIgURE 11: 2D PLOT - OPTICAL PERFORMANCE OF SWITCHABLE TRIPLE-LAYER CUSHION (10\% SAG, 50 X 50 MM FRIT LAYOUT, VARYING OPTICAL FRIT PROPERTIES) - ANGLE DEPENDENT TRANSMITTANCE IN OPEN AND CLOSED MODE

For better visualization of the three-dimensional data radial contour plots were generated, shown in Figure 12. From the summary data plots in Figure 12, again, the distinct optical behaviour of the switchable cushions in open and closed mode can be observed. In open mode all cushion specimens show, in comparison to diagonal incident angles (azimuth $45^{\circ}$ ), a higher mean transmittance when the rays are incident perpendicular to the cushion edge (azimuth $0^{\circ}$ ), with a difference ranging from $0.1 \%$ to $4.2 \%$, for high and low transmittance frit prints, respectively. This may result from the square boundary geometry but also from the frit grid layout which has a higher percentage of optical overlap in diagonal ray direction. However, from Figure 12 it also can be seen that the opposite optical behaviour is the case for the closed mode, but with a much smaller effect. For the closed mode azimuth angles at $45^{\circ}$, perpendicular to the cushion, result in marginally higher mean flux rates, with a comparative difference to perpendicular azimuth angles $\left(0^{\circ}\right)$, ranging from $0.1 \%$ to $0.7 \%$ for high and low transmittance frit prints, respectively. In both operational modes the transmittance of all cushion samples is higher at low altitude angles $\left(15^{\circ}\right)$ than close to the zenith, $90^{\circ}$ angle, with a mean difference ranging from $0.6 \%$ to $18.1 \%$ at open and from $0.6 \%$ to $5.9 \%$ at closed mode, for high and low transmittance frit prints, respectively. This may result, in case of the open mode, from the near perfect alignment of the frit pattern of both, middle and outer layer, in the optical view direction of the zenith. Even though the layers are physically separated, solar rays are effectively blocked out in this precise position and orientation. Only a small proportion of the radiation flux is transmitted through the frit print itself and re-reflected internally by the concave curvature of the cushion layer, and eventually some percentage is internally reflected and transmitted as a secondary radiation. Comparing the different frit prints with varying parameters of transmittance and reflectance showed that the mean degree of influence on the cushion performance is related to the optical properties of the frit and the incidence angle of radiation. From the contour plots of Figure 12 it can be noted that in all eight cases of this study the angular hemispheric transmittance shows similar patterns, but at different flux rates. 
Cushion with frit print type $1(T=5, R=95, A=0)$ open
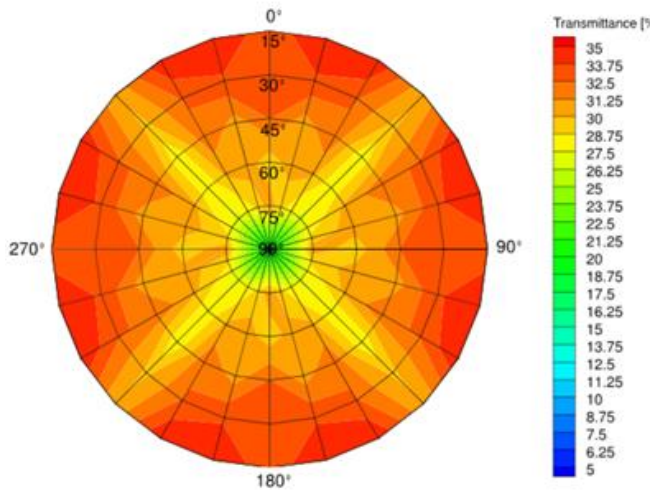

Cushion with frit print type $2(T=20, R=80, A=0)$ open
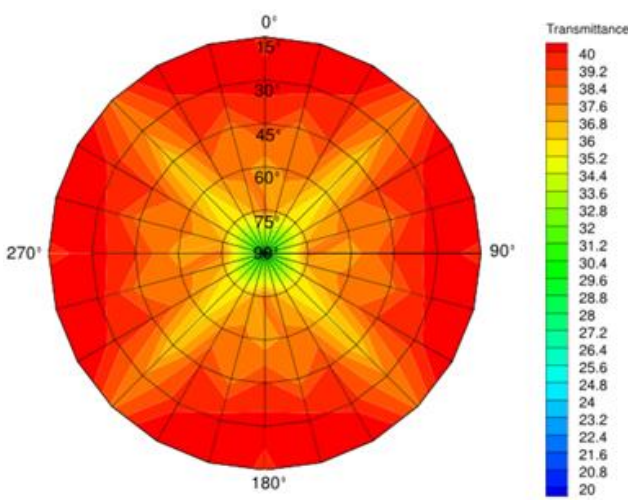

Cushion with frit print type $3(T=35, R=65, A=0)$ open
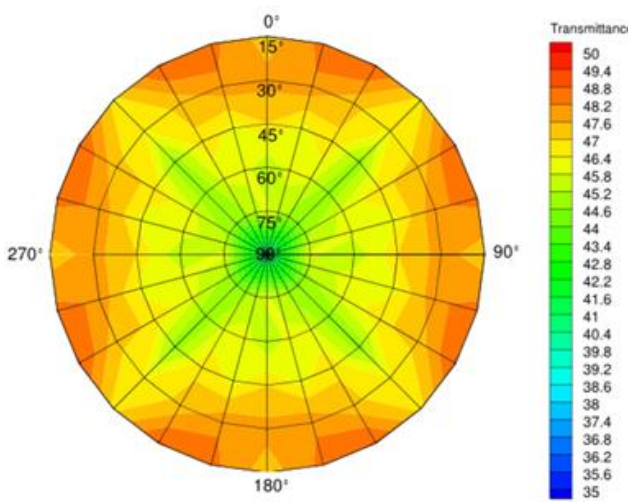

Cushion with frit print type $4(T=50, R=50, A=0)$ open
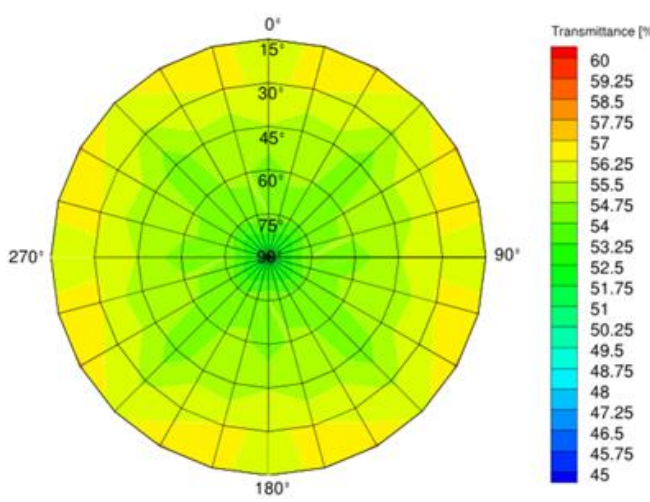

Cushion with frit print type $1(T=5, R=95, A=0)$ closed

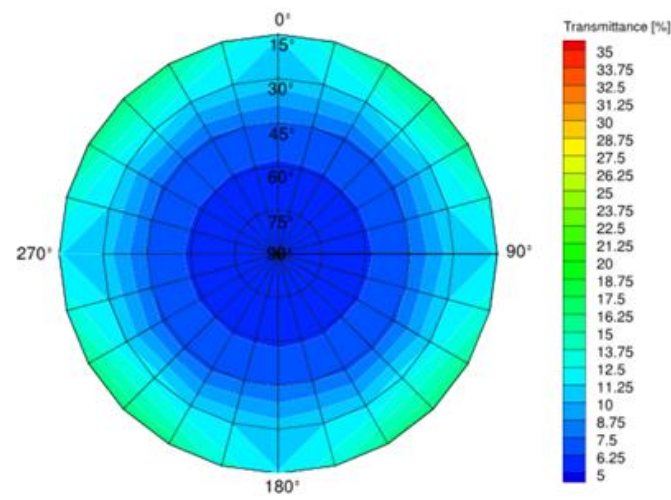

Cushion with frit print type $2(T=20, R=80, A=0)$ closed

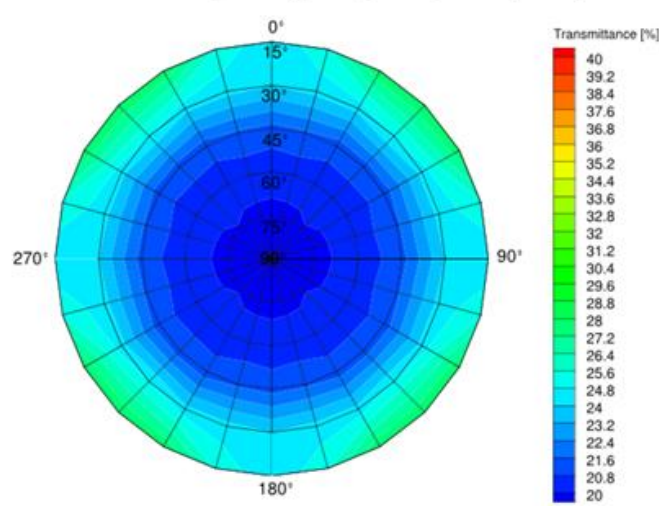

Cushion with frit print type $3(T=35, R=65, A=0)$ closed

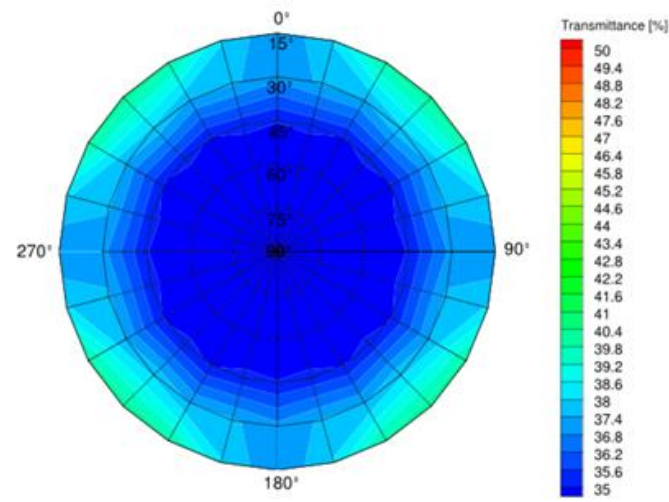

Cushion with frit print type $4(T=50, R=50, A=0)$ closed

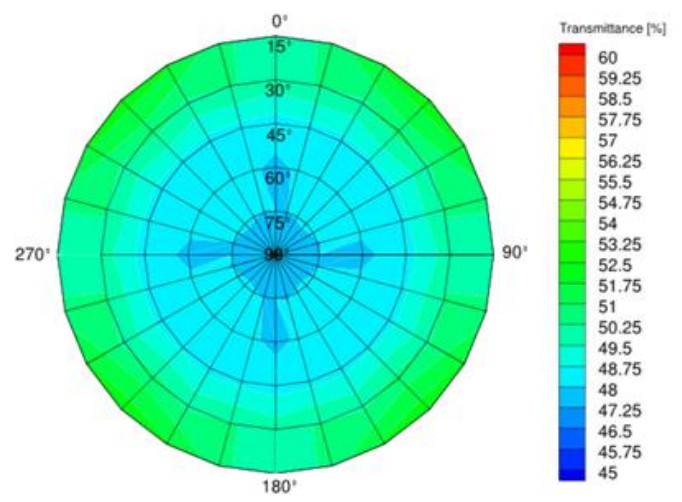


Cushion with frit print type $5(T=65, R=35, A=0)$ open

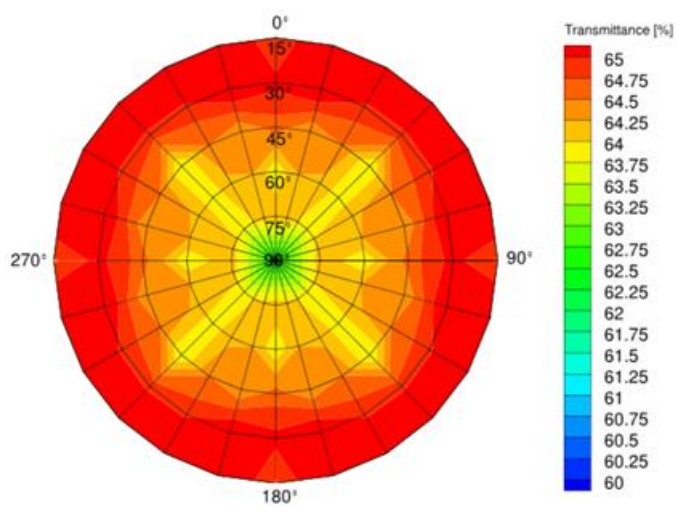

Cushion with frit print type $6(T=80, R=20, A=0)$ open

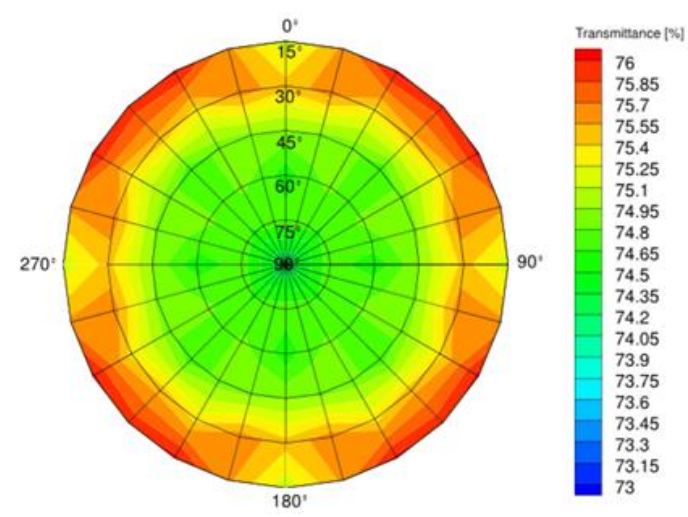

Cushion with frit print type $7(T=95, R=5, A=0)$ open
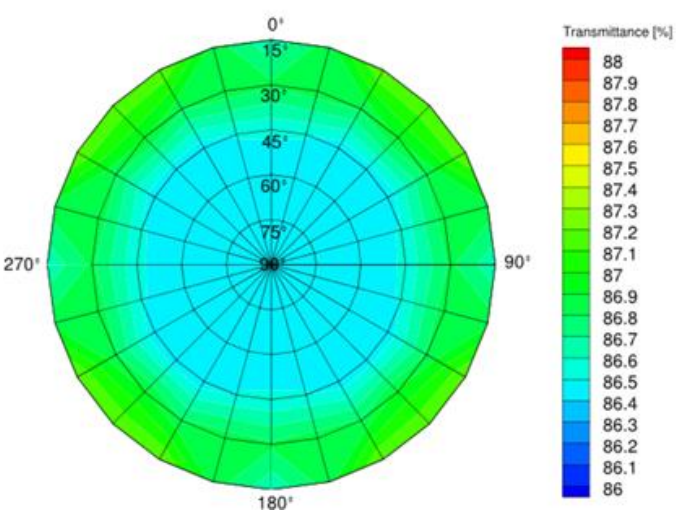

Cushion with frit print type $8(T=5, R=61, A=34)$ open
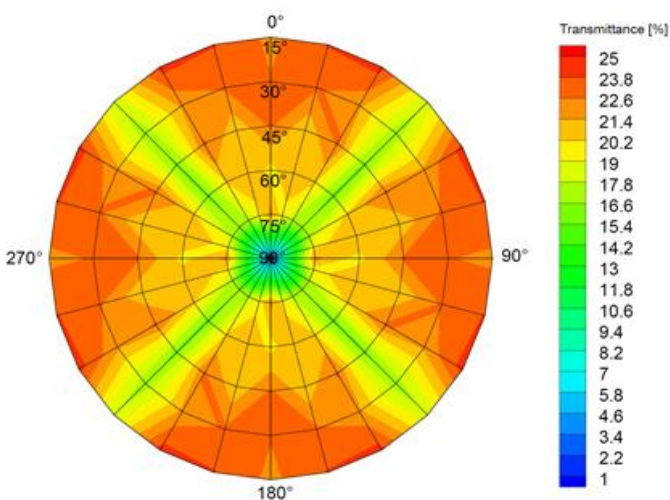

Cushion with frit print type $5(T=65, R=35, A=0)$ closed

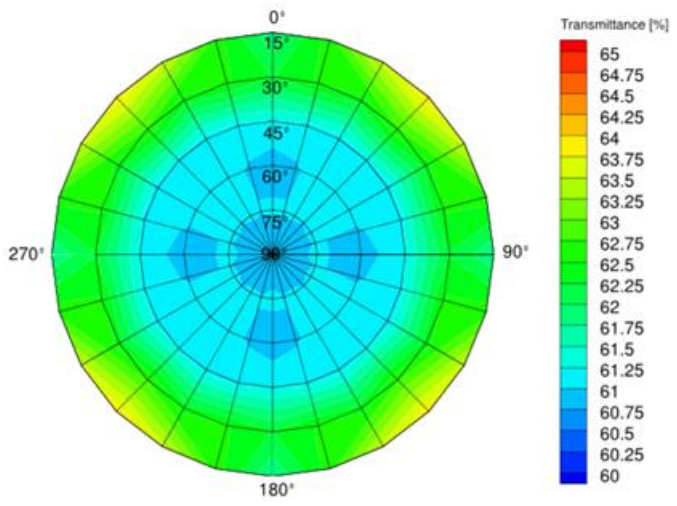

Cushion with frit print type $6(T=80, R=20, A=0)$ closed

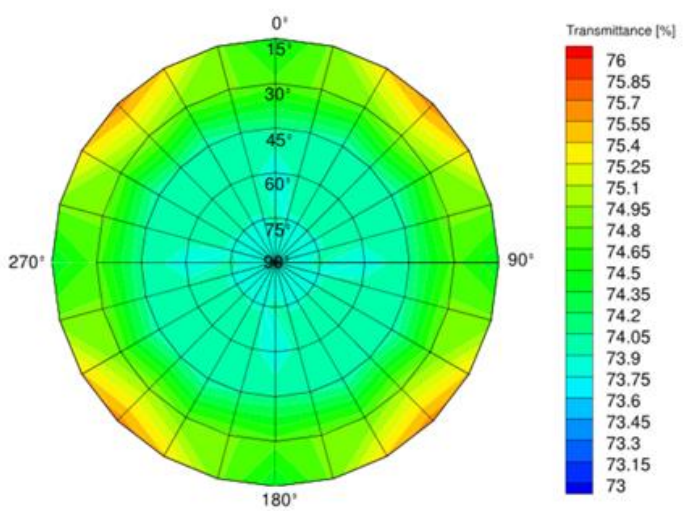

Cushion with frit print type $7(T=95, R=5, A=0)$ closed

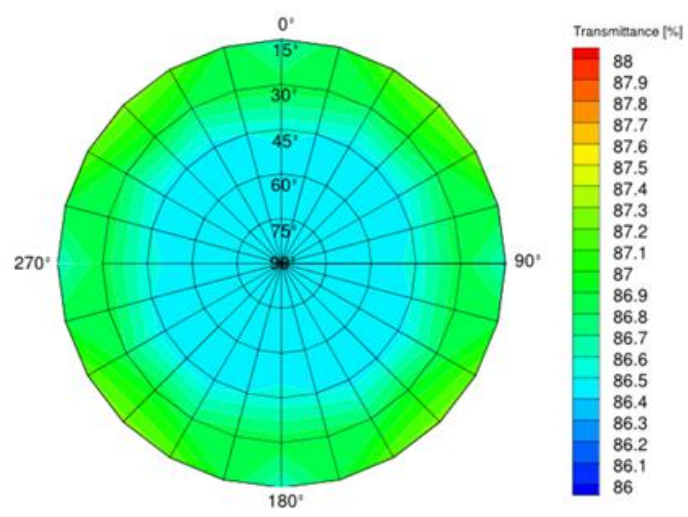

Cushion with frit print type $8(T=5, R=61, A=34)$ closed

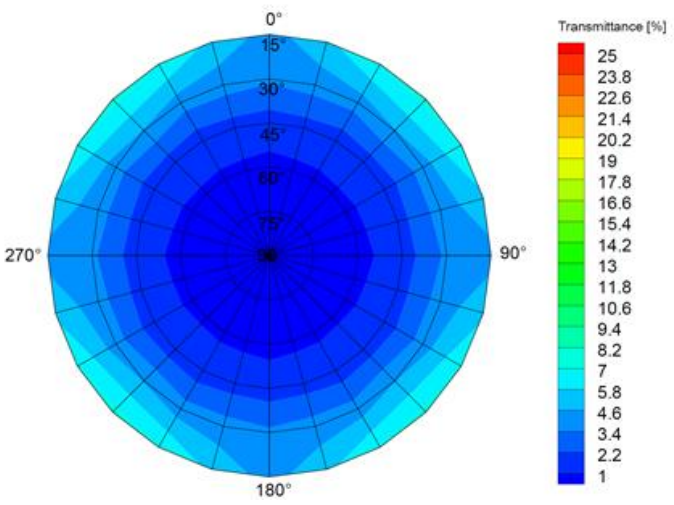

Figure 12: 3D PLOT - OPtiCAL PERFormanCE Of SWITCHABLE TRIPLE-LAYER CUSHION (10\% SAG, 50 x 50 MM FRIT LAYOUT, VARYING OPTICAL FRIT PROPERTIES) - ANGLE DEPENDENT TRANSMITTANCE IN OPEN AND CLOSED MODE 
Based on the ray-tracing results hemispheric mean transmittance values were calculated for each of the cushion samples with a different frit print, in open and closed mode shown in Table 4. The comparative graph of Figure 13 shows that the calculated mean transmittance follows a general trend towards a more distinctive optical behaviour between the two operational modes the lower the transmittance and higher the reflectance of the frit ink are. The cushion with a low transmittance (5\%) and high reflectance (95\%) frit print (Frit Print 1) achieves the lowest overall mean transmittance of all analysed samples, with $31.1 \%$ in open and $8.8 \%$ in closed mode, respectively. But nevertheless, the mean difference in transmittance between the open and closed mode is representing with $22.3 \%$ the highest difference of transmittance of all simulated frit prints. From a design perspective this finding might suggest that highly reflective and opaque frit inks could be more effective compared to frit inks with an inverse ratio, because a distinctive optical behaviour of the two modes is advantageous for a switchable building envelope, which is expected, to adapt to temporary changes of climate, weather and solar radiation. This combination of findings provides support for the premise that, the higher the difference in transmittance between the two modes, the more effective is the radiation control of the switchable ETFE foil cushion. While a gradual transmittance control of the cushion would be desirable for future developments, only a two-mode switch can be achieved with this system. Therefore, it is important to set the optical properties of the frit print at the best possible thresholds for transmittance and reflectance during the design phase in order to achieve the desired energy performance of the building envelope.

TABLE 4: OPTICAL PERFORMANCE OF SWITCHABLE TRIPLE-LAYER ETFE CUSHIONS WITH DIFFERENT FRIT PRINT PROPERTIES IN OPEN AND CLOSED MODE

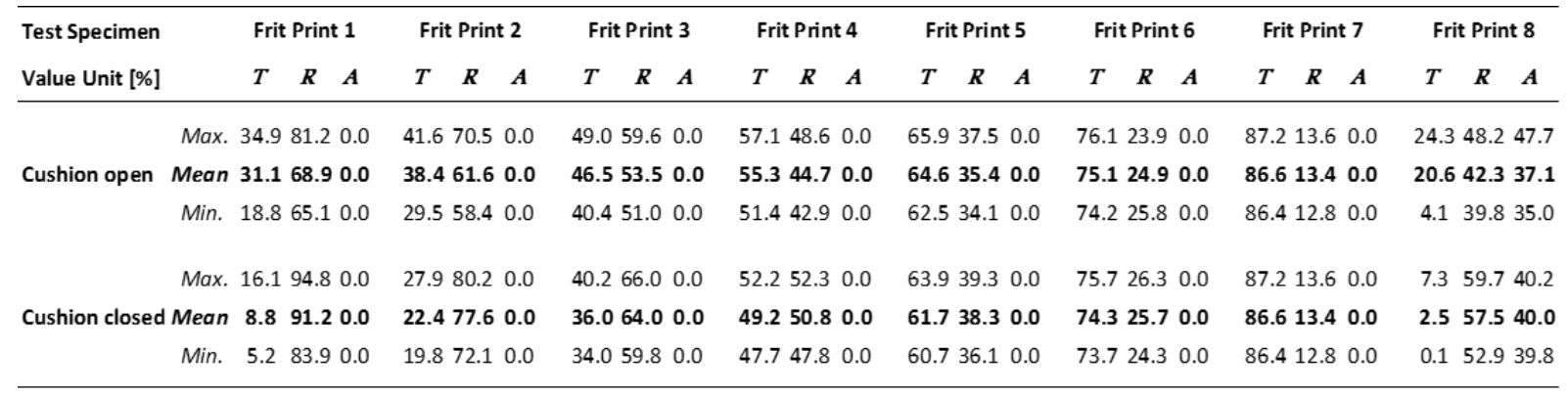

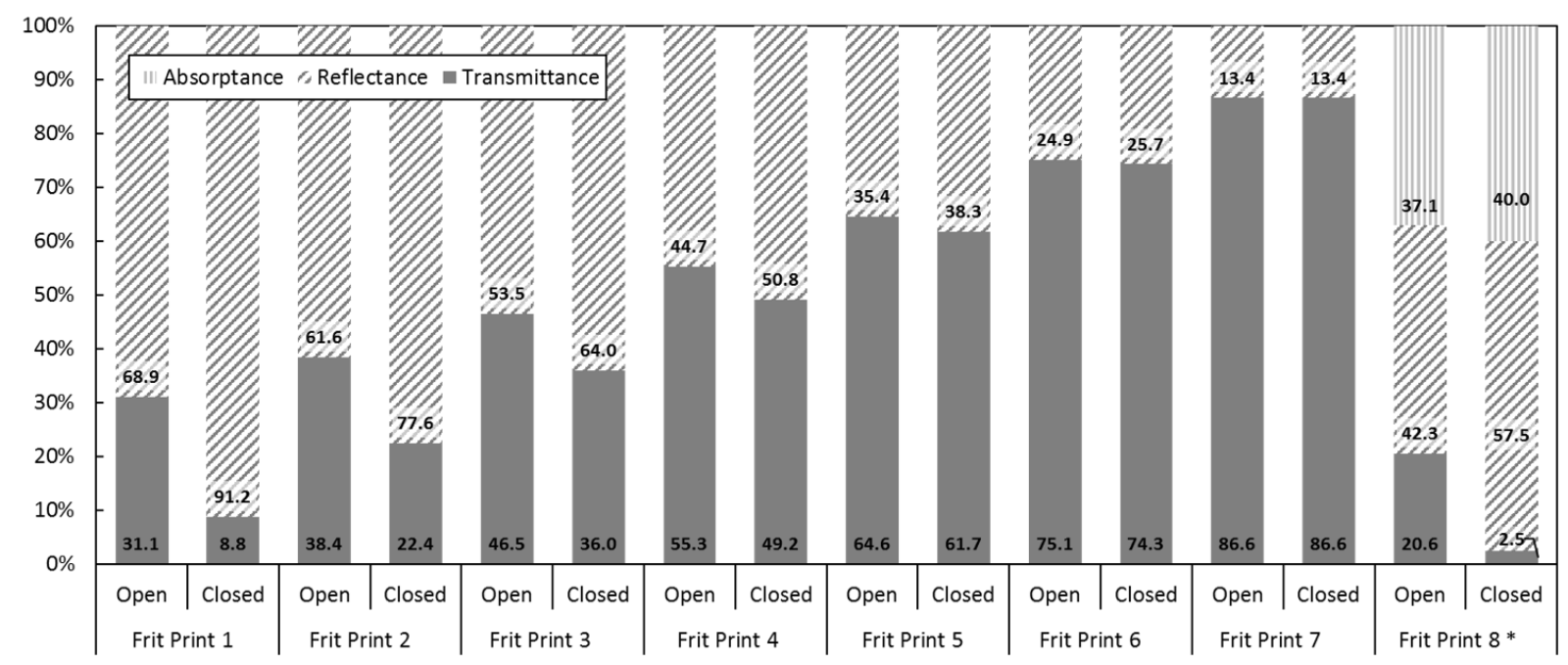

FIGURE 13: OPTICAL PERFORMANCE OF SWITCHABLE ETFE CUSHIONS WITH DIFFERENT FRIT PRINT PROPERTIES

Having discussed the optical behaviour, the final section addresses the energy and lighting performance, in order to provide more insights into the performance of switchable ETFE foil cushions in buildings. Results of 
the optical study (Table 4 and Figure 13) were combined in a comprehensive energy simulation setting with a realistic building model, comparing selected samples of switchable ETFE foil cushions with conventional glazing types.

\subsection{Energy performance of buildings incorporating switchable ETFE foil cushions}

This last section reports on the results obtained from the integrated energy simulation and discusses the thermal, lighting and energy performance of the building with different facade solutions including the switchable ETFE foil cushion and conventional glazing. In order to understand window and cushion thermal performance, the Solar Heat Gain Coefficient (SHGC) was used for the analysis. The SHGC, which is the fraction of the incident solar radiation that enters the room after passing through the window, is determined by dividing the window total heat gain by the incident solar radiation (Eq. 1) [80]. The incident solar radiation rate represents the total received solar radiation on the external surface of the glazing unit. The window total heat gain shown comprises the incident radiation that enters the room in the form of transmitted radiation or as secondary heat gains due to the fraction of radiation that has been absorbed in different layers of the window and transmitted to the interior by conduction, convection and radiation. A higher SHGC means that a larger amount of solar heat will be transmitted through the window into the interior space; while a lower SHGC means that less solar heat gain will occur. Figure 14 shows the annual average solar heat gain coefficient (SHGC) of the switchable ETFE foil cushion (using a cushion with frit print $8^{*}$ as an example) in comparison with clear double glazing and reflective glazing under the cold climatic condition, in Birmingham. The graph shows slopes of points which represent the trend of heat gain rate of the window unit for a range of solar radiation incident rates. The slope of the clear double glazing ( $k 1)$ and reflective glazing $(k 2)$ are approximately 0.60 and 0.29 and keep at a constant level throughout the year, which is in accordance with the stable properties of clear DG and reflective DG. Due to the effect of high solar reflection of the reflective DG, it results in a lower SHGC than for the clear DG. The values of $k 3$ and $k 4$ are obtained under the open and closed modes of the foil cushion with frit print $8^{*}$, which are approximately 0.10 and 0.24 , similar to the reflective DG and much lower than the clear DG. This means, that when the ETFE is in open mode, less solar energy is admitted, in comparison with clear DG. With the increase of the solar radiation rate, the illuminance gradually reaches high levels, thus triggering the switching mechanism of the ETFE foil cushion from open to closed mode. The orange points in the graph are gradually replaced by grey points, which represent the response of the cushion to the increasing level of illuminance. As a result, the annual average SHGC of the ETFE cushion decreases to 0.10 , which is significantly lower than clear and reflective DG, resulting in less solar energy transmitted through the façade.

$$
\text { Solar Heat Gain Coefficient }(\mathrm{SHGC})=\frac{\text { Window Heat Gain Rate }\left[\mathrm{W} / \mathrm{m}^{2}\right]}{\text { Incident Solar Radiation Rate }\left[\mathrm{W} / \mathrm{m}^{2}\right]}
$$

\section{EQUATION 1}

Daylighting performance is a key factor to be considered when designing window systems for buildings that are required to satisfy demands of low energy consumption and high occupancy comfort [81]. Useful daylighting illuminance (UDI) is a metric which is used to evaluate the daylighting performance of window systems and has been extensively used in previous research [81-83]. The concept of UDI refers to a climatedata based range of illuminance and it could be divided into three bins which are $<100$ lux, 100-2000 lux and $>2000$ lux. The three categories are considered as an undersupply bin, a useful bin and an oversupply bin, respectively [81]. Accordingly, the aim is to maintain the illuminance levels of Zone 1 within the useful range. If illuminance levels from natural lighting fall below 200 lux, artificial lighting is turned on, and if illuminance passes the upper threshold of 2000 lux the switchable ETFE foil cushion changes to closed mode. Therefore, in this study, a more detailed subdivision is needed for the useful bin which is subdivided into a range of 100- 
200 lux and 200-2000 lux. When illuminance is in the range between 100-200 lux it is considered as the tolerable range for humans. However, illuminance in this range requires the supplementary use of artificial lighting which would cause undesired additional energy consumption. When illuminance is in the range between 200-2000 lux it is considered as the most desirable and pleasant illuminance range for human comfort.

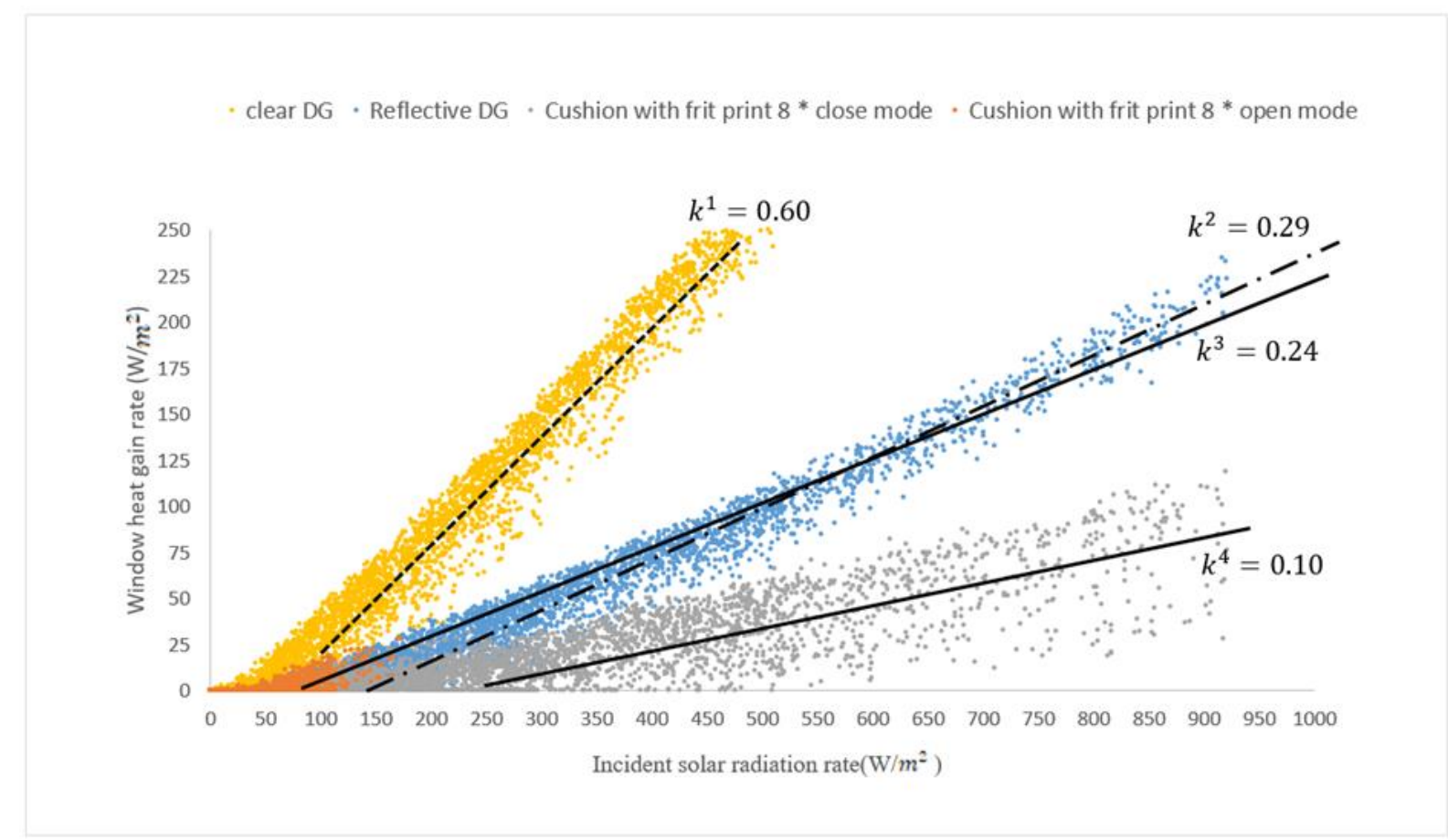

FIGURE 14: INCIDENT SOLAR RADIATION RATE DIVIDED BY WINDOW HEAT GAIN OF CUSHION WITH SWITCHABLE FRIT PRINT $8 *$ CLEAR AND REFLECTIVE DOUBLE GLAZING UNDER COLD CLIMATE CONDITIONS.

During the simulation the daylighting illuminance of Zone 1 was reported every ten minutes for a calendar year, based on a Monday to Friday working schedule. The collected data was filtered and divided into four bins according to the UDI categories. Six types of façade solutions were evaluated under hot and cold climate conditions, including clear DG, reflective DG, and the ETFE foil cushion with frit print types 1, 3, 5 and 8 *. The percentage of time where the UDI ranges were achieved in Zone 1 is shown in Figure 15. As indicated in Figure $15 \mathrm{~A}$ ), clear DG shows the poorest daylighting performance among the six types of façade, under the cold climate. The most desirable daylight condition (200 lux $<U D \mid<2000$ lux) is only achieved during $4.7 \%$ of the evaluated time period. This results mainly in a higher percentage of working hours with oversupplied daylight, caused by a high visible transmittance of clear DG. Therefore, clear DG also has the highest workinghours proportion in the oversupply bin (>2000 lux) which is $91.7 \%$. This situation could be improved to $82.7 \%$, $17.1 \%, 61.2 \%, 87.3 \%$ and $90.6 \%$ by changing the glazing material to either reflective DG or ETFE foil cushions with frit print $8^{*}, 1,3$ and 5, respectively. It can be noted from the results that ETFE foil cushions with frit print $8^{*}$ could eliminate most of the oversupply of daylight as it maintains the lowest visible transmittance among the six evaluated glazing types. Due to the low visible light transmittance of ETFE cushions with frit print, they all give a rise in the undersupply daylight bin $\left(<100\right.$ lux). Especially cushions with frit print $8^{*}$ increased the percentage of undersupply daylight hours from $3.2 \%$ to $4.3 \%$, when compared with clear DG. When considering the most desired range of UDI (200 lux-2000 lux), the percentage of hours increased from $4.7 \%$ for clear DG to $13 \%$ and $74.8 \%$ for reflective DG and ETFE cushion $8 *$, respectively. The results in general establish that cushion $8^{*}$ could deliver a better daylighting performance. However, a cushion with higher visible light transmittance might not significantly improve the daylight quality, when compared with reflective DG. As such, cushions 3 and 5 have $8.7 \%$ and $5.7 \%$ percentage working hours within the 200 lux- 
2000 lux range, respectively. Regarding the lighting energy consumption, ETFE foil cushions with frit print may not be the most optimal choice in comparison to other glazing types, as they have a high proportion of UDI $<100$ lux and 200-2000 lux. When comparing clear DG with cushion $8^{*}$, this proportion will increase from $3.6 \%$ to $8.1 \%$, which would result in a higher electrical energy consumption for artificial lighting. However, lighting energy only accounts for a small proportion in the total building energy consumption, when compared to the demands for heating and cooling. Figure 15 (B) illustrates that the predicted UDI for the six façade types in a hot climate, with an overall performance of all glazing types similar to the cold climate scenario.
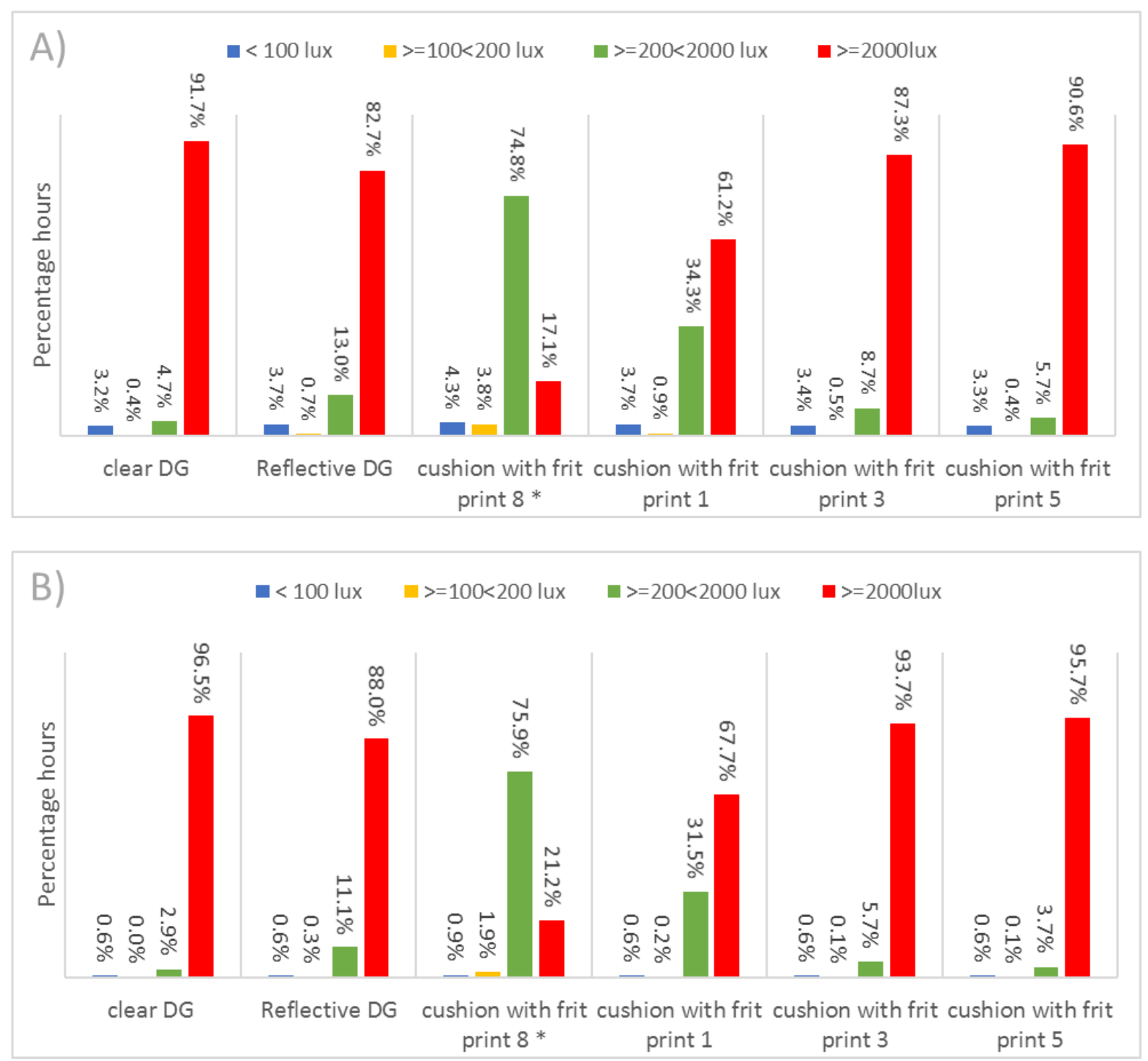

Figure 15: PERCENTAGE TIME OF UDI IN COLD CLIMATE (A), PERCENTAGE TIME OF UDI IN HOT CLIMATE (B)

In this section, results from the energy simulation have been reported for the six façade types under cold and warm climate. Window systems can significantly affect the energy demand for cooling, heating and lighting and thus contribute to the total building energy consumption. For this reason, annual energy consumption of the building is further discussed by focussing on the aspects of lighting, heating and cooling, expressing the results in terms of $\mathrm{kWh} / \mathrm{m}^{2}$. Figure $16(\mathrm{~A})$ shows, that the predicted energy consumption reaches the highest value of $322.2 \mathrm{kWh} / \mathrm{m}^{2}$ under cold climate conditions when using clear DG, and gradually decreases when replacing the DG with cushion $5,3,1$ or $8^{*}$. In comparison with clear DG the maximum saving of $60.8 \%$ on the annual energy consumption was achieved with the ETFE foil cushion with frit print $8^{*}$. A possible explanation for this is the significant energy reduction for cooling loads. It is apparent from Figure 16 (A) that 
a decreasing trend of the cooling load leads to a reduction of $88.1 \%$ of the energy consumption when replacing clear DG with ETFE foil cushions with frit print $8^{*}$. This big effect on the energy consumption for cooling may be attributed to the low SHGC of ETFE foil cushions. Even when comparing with reflective DG, ETFE foil cushions with frit print $8^{*}$ and 1 still deliver a better energy performance under cold climate conditions, with an annual saving of $20.3 \%$ and $18.9 \%$ respectively. When considering the energy consumption for lighting, a 5.1\% increase was reported when comparing cushion $8^{*}$ with clear DG. This result matched those observed in earlier UDI ( $<100$ lux and 100-200lux) analysis. ETFE foil cushions prove to be more advantageous under hot climate conditions where cooling is predominantly required and larger energy saving can be achieved. As shown in Fig. 16 (B) the annual saving could reach $78.9 \%$ and $44.9 \%$, respectively, when using ETFE foil cushions with frit print $8 *$ instead of clear DG and reflective DG.
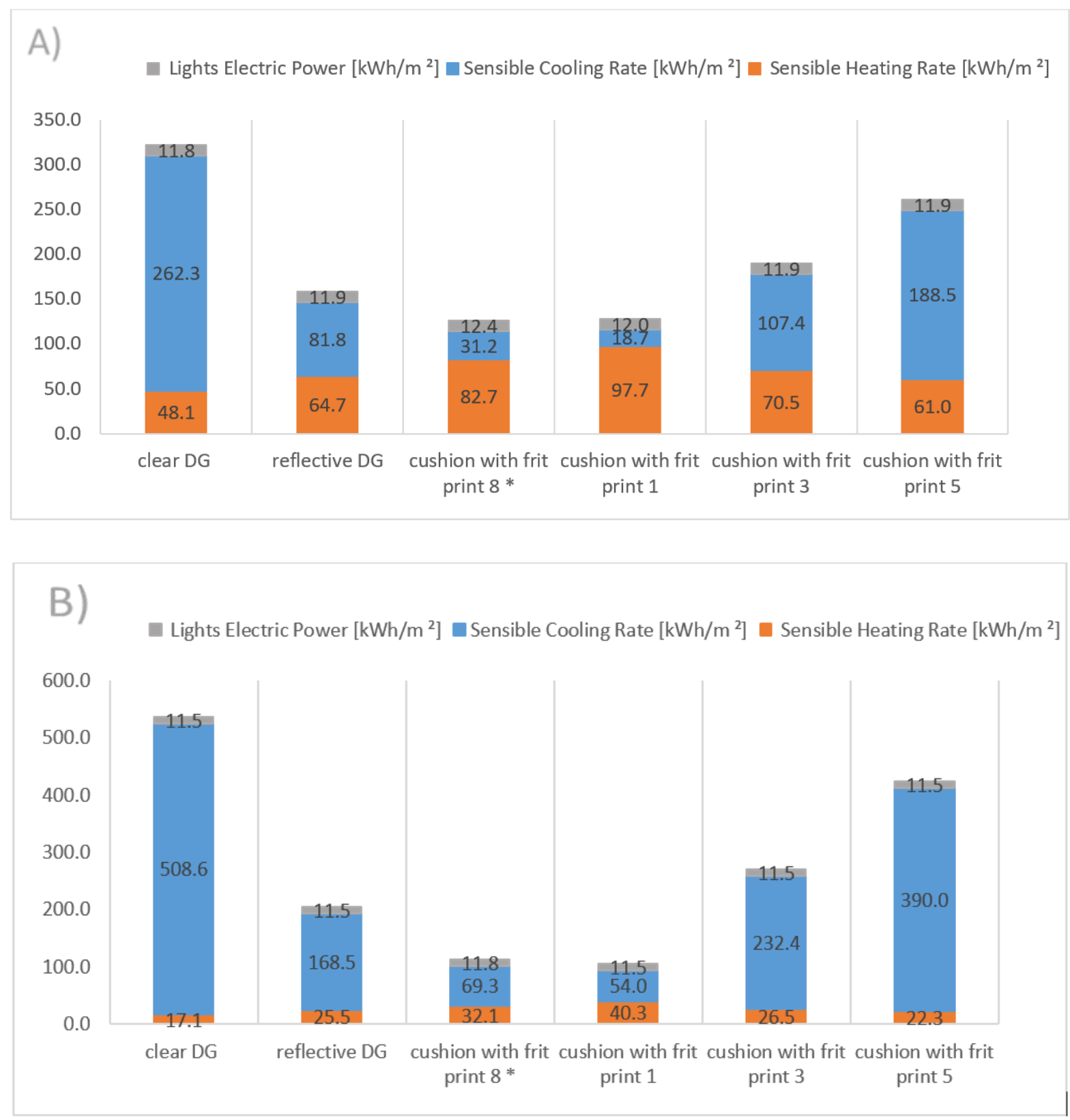

Figure 16: ANNUAL ENERgY CONSUMPTION IN COLD CLIMATE (A) AND ANNUAL ENERGY CONSUMPTION IN HOT CLIMATE (B) 


\section{Conclusions}

In this investigation, the aim was to assess the optical behaviour of switchable multilayer foil constructions and to determine the impact on the energy performance of buildings. The study has shown that switchable ETFE foil cushions can improve the energy performance of buildings and outperform common glazing solutions, like DG and reflective DG, also in terms of daylighting. The results of this investigation suggest that the two modes of the kinetic shading mechanism allow the building envelope to adapt actively to the variable climate conditions and thus reduce the energy demand for heating, cooling and lighting of the building by up to $48.5 \%$, compared to DG and reflective DG. It was also shown that the employment of switchable ETFE foil cushions may lead to better natural lighting conditions. The results indicate that, in comparison to reflective glazing, 64.8\% more hours of useful daylight might be achieved in spaces covered by switchable ETFE cushions. This has positive implications on both the visual comfort of the building's occupiers and the energy performance of the building, because less electric lighting is needed. While the analysis showed that the optical performance of switchable ETFE cushions is highly dependent on the solar incidence angle, design parameters like the sag and frit print size seem to have only limited influence. The optical properties of frit prints, however, play a key role. Frit prints with a higher reflectance and lower transmittance amplified the distinctive optical behaviour between open and closed mode and thus increase the adaptive performance of switchable ETFE cushions.

Several limitations to this pilot study need to be acknowledged. Firstly, the cushion dimensions might not be representative of the most common building applications of ETFE foil, but they clearly indicate a trend in performance. Secondly, the used material data from Liu and Knippers [26, 27] can only serve as a reference that might need to be updated with complete spectral data from material suppliers or direct tests. Also, the evaluation of more than one building type under different scenarios might be considered for further studies, to confirm and generalize the predicted benefits of the switchable ETFE foil cushions on the energy performance of buildings.

Notwithstanding these limitations, the study increases the understanding of the building physics of adaptable multilayer foil constructions and allows to forecast the performance of future design schemes and developments of high performance foil coatings. Production Industry as well as planners and designers might benefit from the generated benchmark values of energy performance as this allows to cost-in the operational savings into the whole construction investment, creating confidence in implementing innovative technologies, such as switchable ETFE cushions, to enhance sustainability of buildings. Future research on this topic would benefit from experimental investigation or post occupancy studies for validation of the simulation results. Further potential is also seen in foils having modified optical properties or new printing inks and techniques which could possibly improve optical performance of multilayer cushions for more effective shading mechanism, thus enhancing energy performance of future buildings.

\section{Acknowledgements}

This work was supported by the Faculty of Engineering at the University of Nottingham through a PhD studentship awarded to Jan-Frederik Flor.

\section{References}

1. UN Environment and International Energy Agency, Towards a zero-emission, efficient, and resilient buildings and construction sector Global Status Report 2017

2. Singh, R., I.J. Lazarus, and V.V.N. Kishore, Uncertainty and sensitivity analyses of energy and visual performances of office building with external venetian blind shading in hot-dry climate. Applied Energy, 2016. 184: p. 155-170.

3. Zhang, T., et al., The application of air layers in building envelopes: A review. Applied Energy, 2016. 165: p. $707-734$. 
Berger, J. and N. Mendes, An innovative method for the design of high energy performance building envelopes. Applied Energy, 2017. 190: p. 266-277.

5. U.S. Energy Information Administration, International Energy Outlook - Executive Summary. 2017.

6. Pérez-Lombard, L., J. Ortiz, and C. Pout, A review on buildings energy consumption information. Energy and Buildings, 2008(40): p. 394398.

Lin, Y.-H., et al., Design optimization of office building envelope configurations for energy conservation. Applied Energy, 2016. 171: p. 336346.

Lei, J., J. Yang, and E.-H. Yang, Energy performance of building envelopes integrated with phase change materials for cooling load reduction in tropical Singapore. Applied Energy, 2016. 162: p. 207-217.

Peng, J., et al., Numerical investigation of the energy saving potential of a semi-transparent photovoltaic double-skin facade in a coolsummer Mediterranean climate. Applied Energy, 2016. 165: p. 345-356.

International Energy Agency, Transition to sustainable buildings - Strategies and oportunities to 2050 - Executive Summary. 2013 , (C) OECD/IEA.

Peng, J., et al., Investigation on the annual thermal performance of a photovoltaic wall mounted on a multi-layer façade. Applied Energy, 2013. 112: p. 646-656.

Wang, M., et al., Comparison of energy performance between PV double skin facades and PV insulating glass units. Applied Energy, 2017. 194: p. 148-160.

Peng, J., L. Lu, and H. Yang, An experimental study of the thermal performance of a novel photovoltaic double-skin facade in Hong Kong. Solar Energy, 2013. 97: p. 293-304.

Pacheco, R., J. Ordó nez, and G. Martínez, Energy efficient design of building: A review. Renewable and Sustainable Energy Reviews, 2012(16): p. 3559-3573.

Chen, X. and H. Yang, A multi-stage optimization of passively designed high-rise residential buildings in multiple building operation scenarios. Applied Energy, 2017. 206: p. 541-557.

Wang, M., et al., Assessment of energy performance of semi-transparent PV insulating glass units using a validated simulation model. Energy, 2016. 112: p. 538-548. Structures STRUCTURAL MEMBRANES 2013, K.-U. Bletzinger, B. Kröplin, and E. Oñate, Editors. 2013: Barcelona, Spain. Biloria, N. and V. Sumini, Performative Building Skin Systems: A morphogenomic approach towards developing real-time adaptive building skin systems. International journal of architectural computing, 2009. 07(04): p. 643 - 675. Francesco Goia, et al., Towards an Active, Responsive, and Solar Building Envelope. Journal of Green Building, 2010. 5(4): p. 121-136. 2010. 2(2): p. 140-157 Chiu, S.K. and E.S. Lin, Transformable Tensile Façade: Performance assessment on energy, solar and daylighting, in Advanced Building Skins. 2015: Graz. p. 11.

Lippke, R., Folien als transparente Elemente in der Fassade - mechanische und bauphysikalische Eigenschaften, in Planen Bauen Umwelt. 2009, Technische Universität Berlin: Berlin, Germany. p. 272.

Ward, J. et al., Internal environment in ETFE foil covered building enclosures, in TensiNet Symposium 2010 - Tensile Architecture: Connecting Past and Future, H. Bögner-Balz and M. Mollaert, Editors. 2010: University of Architecture, Civil Engineering and Geodesy (UACEG), Sofia, Bulgaria. (2010) p. 129-138.

Kaufmann, A., K. Sedlbauer, and M. Sieder, Wärmetechnische Besonderheiten von Membrankissenkonstruktionen. Bautechnik 90 2013(Heft 7): p. 7.

31. Mainini, A.G., et al., Transparent Multilayer ETFE Panels for Building Envelope: Thermal Transmittance Evaluation and Assessment of Optical and Solar Performance Decay due to Soiling. Energy Procedia, 2014. 48: p. 1302-1310.

32. Lau, B., et al., Understanding Light in Lightweight Fabric (ETFE Foil) Structures through Field Studies. Procedia Engineering, 2016. 155: p. 479-485

33. Hu, J., et al., Buildings with ETFE foils: A review on material properties, architectural performance and structural behavior. Construction and Building Materials, 2017. 131: p. 411-422.

34. Lamnatou, C., et al., Ethylene tetrafluoroethylene ETFE material - Critical issues and applications with emphasis on buildings_. Renewable and Sustainable Energy Reviews, 2017: p. 16.

35. Hase, W., et al., Adaptive mehrlagige textile Gebäuedehüllen, in Forschungsinitiative »Zukunft Bau«. 2011, Institut für Leichtbau Entwerfen und Konstruieren: Universität Stuttgart. p. 125.

36. Wypych, G., Handbook of Polymers. Second Edition ed. 2016: ChemTecPublishing.

37. Cremers, J. and H. Marx, 3D-ETFE: Development and evaluation of a new printed and spatially transformed foil improving shading, light quality, thermal comfort and energy demand for membrane cushion structures. Energy Procedia, 2017. 122(Supplement C): p. 115-120.

38. Cremers, J. and H. Marx, Comparative Study of a New IR-absorbing Film to Improve Solar Shading and Thermal Comfort for ETFE Structures. Procedia Engineering, 2016. 155: p. 113-120.

39. Cremers, J. and H. Marx, Improved daylight comfort by a new 3D-foil that allows to trade off solar gains and light individually, in Structural Membranes 2017, K. Bletzinger, E. Oñate, and B. Kröplin, Editors. 2017, International Center for Numerical Methods in Engineering (CIMNE): Munich, Germany. p. 505. Bart de Boer, G.J.R., Roel Loonen, Marija Trčka, Jan Hensen, Wim Kornaat, Climate adaptive building shells for the future - optimization with an inverse, in ECEEE 2011 Summer study. 2011, Energy efficiency first: the foundation of a low-carbon society: Belambra Presqu'île de Giens, France.

41. Wang, J., L. Beltran, and J. Kim, From Static to Kinetic: A Review of Acclimated Kinetic Building Envelopes, in Solar Conference, World renewable energy forum. 2012, American Solar Energy Society: Boulder, Colorado, USA.

42. Loonen, R.C.G.M., et al., Climate adaptive building shells: State-of-the-art and future challenges. Renewable and Sustainable Energy Reviews, 2013. 25(Supplement C): p. 483-493. 

buildings. Journal of Facade Design and Engineering, 2015. 3: p. 143-163.

44. Attia, S., Favoino, F., Loonen, R., Petrovski, A., Monge-Barrio, Adaptive Façades System Assessment: An initial review, in 10th Conference on Advanced Building Skins. 2015, COST Action TU1403 - Adaptive Facades Network: Bern, Switzerland.

45. Konstantoglou, M. and A. Tsangrassoulis, Dynamic operation of daylighting and shading systems: A literature review. Renewable and Sustainable Energy Reviews, 2016. 60: p. 268-283.

46. Sun, Y. and e. al., A Review of Thermal and Optical Characterisation of Complex Window Systems and Their Building Performance Prediction. Applied Energy, 2018. 222C: p. 729-747.

47. Sun, Y., et al., Development of a comprehensive method to analyse glazing systems with Parallel Slat Transparent Insulation material (PSTIM). Applied Energy, 2017. 205: p. 951-963.

48. LeCuyer, A., ETFE. Technology and Design. 2008, Basel, Switzerland: Birkhauser Verlag AG.

49. Jeska, S., Transparent Plastics - Design and Technology. 2008, Basel - Boston - Berlin Basel, Switzerland printed in Germany: Birkhäuser Verlag AG.

50. Forster, B. and M. Mollaert, European Design Guide for Tensile Surface Structures. 2004: Tensinet.

Robbin, T., Engineering a new architecture. 1996, Printed in United States of AmericaQuebecor-Eusey Press, Leominster, Massachusetts: Yale University Press New Haven and London. 138.

Poirazis, H., Energy modelling of ETFE membranes in building applications. 2009.

Schmid, G., Neues Bauen mit ETFE-Folien, in AB Archiv des Badewesens. 2009: Essen, Germany.

Gómez-González, A., J. Neila, and J. Monjo, Pneumatic Skins in Architecture. Sustainable Trends in Low Positive Pressure Inflatable Systems. Procedia Engineering, 2011. 21: p. 125-132.

Chilton, J., Lightweight envelopes: ethylene tetra-fluoro-ethylene foil in architecture. Construction Materials, 2013. 166(CM6): p. 343-357. Maywald, C. and F. Riesser, Sustainability - The Art of Modern Architecture. Procedia Engineering, 2016. 155: p. 238-248.

Morris, B., Foil Climatic Envelope, in International Symposium on Widespan Enclosures, M. Barnes and M. Dickson, Editors. 2000: University of Bath, UK.

Juaristi, M. and A. Monge-Barrio, Adaptive façades in temperate climates. An in-use assessment of an office building, in 11th Conference on Advanced Building Skins. 2016: Bern, Switzerland.

Sun, Y.Y., et al., Experimental measurement and numerical simulation of the thermal performance of a double glazing system with an interstitial Venetian blind. Building and Environment, 2016. 103: p. 111-122.

61. Sun, Y.Y., et al., Thermal evaluation of a double glazing facade system with integrated Parallel Slat Transparent Insulation Material (PSTIM). Building and Environment, 2016. 105: p. 69-81. Wu, Y., et al., Smart solar concentrators for building integrated photovoltaic façades. Solar Energy, 2016. 133: p. 111-118.

63. https://energyplus. net/. accessed March 2018.

64. Kai-Uwe Bletzinger, E.R., A General Finite Element approach to the form finding of tensile structures by the updated reference strategy. International Journal of Space Structures, 1999. 14(2): p. 131-145.

65. Dieter Ströbel, P.S., Jürgen Holl, Holistic Calculation of (Multi)-Chambered ETFE-Cushions', in Tensinet Symposium [RE]THINKING lightweight structures 2013: Istanbul, Turkey.

66. Li, P. and Q. Yang, Form Finding and Loading Analysis of ETFE Cushions Using Interaction Numerical Model. Applied Mechanics and Materials 2013(438-439): p. 1812-1815.

67. Roudsari, M.S. and A. Waelkens, A New Approach to Modeling Frit Patterns for Daylight. 2015.

68. Spencer, G.H. and M.V.R.K. Murty, General Ray-Tracing Procedure. Journal Of The Optical Society Of America, 1962. 52(6): p. 672-678.

69. Kämpf, J.H. and J.-L. Scartezzini, Ray-tracing simulation of complex fenestration systems based on digitally processed BTDF data, in CISBAT Conference. 2011: Lausanne, Switzerland.

70. Sun, Y., Y. Wu, and R. Wilson, Analysis of the daylight performance of a glazing system with ParallelSlat Transparent Insulation Material (PS-TIM). Energy and Buildings, 2017(139): p. 616-633.

71. Ahmad Eltaweel, Y.S., Controlling venetian blinds based on parametric design; viaimplementing Grasshopper's plugins: $A$ case study of an officebuilding in Cairo. Energy and Buildings, 2017. 139: p. 31-43.

72. Connelly, K., et al., Transmittance and Reflectance Studies of Thermotropic Material for a Novel Building Integrated Concentrating Photovoltaic (BICPV) 'Smart Window' System. Energies, 2017. 10(11): p. 1889.

73. Dimitriadou, E.A., Computational modelling of the thermal behaviour of an ETFE cushion using IES, in SB13 Portugal - Contribution of Sustainable Building to meet EU 20-20-20 Targets, L. Bragança, M. Pinheiro, and R. Mateus, Editors. 2013 Guimarães, Portugal.

74. Robinson-Gayle, Environmental impact and performance of transparent building envelope materials and systems, in Department of Mechanical Engineering, . 2003, Brunel University. p. 306.

75. Connelly, K., et al., Design and development of a reflective membrane for a novel Building Integrated Concentrating Photovoltaic (BICPV) 'Smart Window' system. Applied Energy, 2016. 182: p. 331-339.

76. Olivieri, L., et al., Integral energy performance characterization of semi-transparent photovoltaic elements for building integration under real operation conditions. Energy and Buildings, 2014. 68: p. 280-291.

77. American Society of Heating, R.a.A.-C.E., Inc.,, Energy Standard for Buildings Except Low-Rise Residential Buildings, in ANSI/ASHRAE/IESNA Addenda ag, ai, aj, ak, ay, bc, and bd to ANSI/ASHRAE/IESNA Standard 90.1-2007. 2007, ASHRAE standard: http://www.ashrae.org. Chartered Institution of Building Services Engineers, Environmental design : CIBSE guide A. 2015: London, UK.

79. Good, P., et al., Spectral reflectance, transmittance, and angular scattering of materials for solar concentrators. Solar Energy Materials \& Solar Cells, 2016(144): p. 509-522.

80. Allen, K., et al., Smart windows-Dynamic control of building energy performance. Energy and Buildings, 2017. 139: p. 535-546.

81. Mardaljevic, J. and A. Nabil, Useful daylight illuminances: A replacement for daylight factors. Energy and Buildings. Energy and Buildings, 2006. 38(7): p. 905-913.

82. Berardi, U. and H.K. Anaraki, Analysis of the Impacts of Light Shelves on the Useful Daylight Illuminance in Office Buildings in Toronto Energy Procedia, 2015. 78: p. $1793-1798$.

83. Sun, Y., et al., Glazing systems with Parallel Slats Transparent Insulation Material (PS-TIM): Evaluation of Building Energy and Daylight Performance. Energy and Buildings, 2018. 159: p. 213-227. 